\title{
The Contribution of GABA-Mediated Inhibitory Mechanisms to Visual Response Properties of Neurons in the Kitten's Striate Cortex
}

\author{
W. Wolf, T. P. Hicks, ${ }^{1}$ and K. Albus \\ Max-Planck-Institut für biophysikalische Chemie, Abteilung Neurobiologie, D-3400 Göttingen, Federal Republic of \\ Germany
}

The effect of the microiontophoretic administration of the GABA antagonist bicuculline methiodide (BMI) on the responses of striate cortical neurons to light stimulation was investigated in kittens ranging in age between 11 and $28 \mathrm{~d}$. The orientation sensitivity of the majority of the $\mathbf{8 8}$ neurons tested for this parameter decreased $(40 \%)$ or was eliminated $(18 \%)$ following the administration of BMI. Changes were seen in all layers and in all neuronal types, and the proportions of neurons that changed their orientation specificity were about the same during the second, third, and fourth postnatal weeks. Twenty-eight percent of the neurons were not affected in their orientation sensitivity by BMI. These neurons were recorded at all postnatal ages; they were located preferentially in layers IV and VI; and they had unimodal, bimodal, or ON-OFF mixed receptive fields. The remaining $14 \%$ of the neurons were initially unresponsive or responded in an erratic way to visual stimulation. These neurons became responsive and even exhibited orientation-specific responses during administration of BMI.

The majority $(56 \%)$ of direction-specific neurons became direction-nonspecific after the administration of BMI. Seventeen percent preserved some direction specificity, whereas $27 \%$ did not show any change at all. The effects of BMI on direction sensitivity were seen at all postnatal ages and on all neuronal types throughout layers III-VI. The majority of neurons unaffected by BMI in their direction sensitivity resided in layer VI. In those cases where orientation sensitivity was reduced, direction sensitivity (if present) was usually diminished as well. However, some neurons were found in which only 1 of the 2 parameters was significantly changed by BMI.

The spatial structure of the receptive field, as revealed by stationary stimulation, was changed significantly by BMI in about half the neurons tested. A straightforward correlation between the alteration of orientation and/or direction sensitivity and changes in receptive-field structure was not found.

The results demonstrate that, in the immature striate cortex, receptive-ficld properties of many neurons are determined by inhibitory processes mediated by GABA, which may also dictate the actual visual responsiveness of the neurons. The dissociations in the effects of BMI on orientation sensitivity, direction

\footnotetext{
Received Apr. 10, 1985; revised Mar. 28, 1986; accepted Apr. 24, 1986.

K.A. was supported by the Deutsche Forschungsgemeinschatt (Schwerpunkt Verhaltensontogenie) and T.P.H. by the MRC of Canada and the Alberta Heritage Foundation for Medical Research. During a portion of this study, T.P.H, was the recipient of a grant from the Max Planck Society, for which grateful acknowledgment is made.

Correspondence should be addressed to K. Albus, M.D., Abt. Neurobiologie, Max-Planck-Institut für biophysikalische Chemie, Am Fassberg 2, D-3400 Göttingen, F.R.G.

I Present address: University of Calgary, Dept. of Medical Physiology, 3330 Hospital Drive N.W., Calgary, Alberta T2N 4N 1, Canada.

Copyright $c 1986$ Society for Neuroscience $0270-6474 / 86 / 102779-17 \$ 02.00 / 0$
}

sensitivity, and receptive-field substructure indicate that the synaptic organization responsible for the various functional parameters is unlikely to be the same.

The receptive-field properties and the responsiveness of neurons in primary visual cortex of kittens in the early postnatal period have recently been described quantitatively in a laminar analysis (Albus and Wolf, 1984). These and other experiments (Bonds, 1979; Fregnac and Imbert, 1978) have extended earlier studies (Blakemore and Van Sluyters, 1975; Hubel and Wiesel, 1963) showing that striate neurons from visually naive animals respond sluggishly to visual stimulation and tend to tire easily. Fewer cells than in the adult exhibit orientation and directional preferences, and the proportions of simple and complex receptive fields are much smaller (Albus and Wolf, 1984). Mature levels of performance have reportedly been achieved beginning approximately 5 weeks postnatally.

The poor performance of many visual cortical neurons, especially during the first and second postnatal weeks, can be explained by the fact that most intracortical axonal projections are still developing (Meyer and Ferres-Torres, 1984), and, accordingly, the synaptic density per neuron is low, approaching only about $10 \%$ of the adult level at around postnatal day 10 (Cragg, 1975a, b; Winfield, 1981, 1983). The finding of small numbers of synapses per neuron, on the other hand, raises doubts that the orientation and direction selectivity, as seen in a few of the neurons in early postnatal cortex, are generated by GABAmediated inhibitory mechanisms, as has been demonstrated convincingly for the majority of neurons in adult visual cortex (Sillito, 1975a, b, 1977, 1979; Sillito et al., 1980). Such doubts are reinforced by the knowledge that, besides the absolute numbers, the relative numbers of inhibitory synapses employing GABA as a transmitter (Wolff et al., 1984a) are much lower in postnatal (less than $1 \%$ ) than in mature $(6 \%)$ cortex (Winfield, 1983; see also Wolff et al., 1984b). It is conceivable in this context that, rather than being generated by intracortical inhibition, the orientation of some neurons in the immature striate cortex could be generated either by excitatory convergence from a. row of neurons in the lateral geniculate nucleus (Hubel and Wiesel, 1962), or by orientation biases of single geniculate neurons sending afferents to visual cortex (Albus et al., 1983; Vidyasagar and Urbas, 1982).

In order to obtain information about the neuronal circuits and the transmitter involved in generating the functional specificity of neurons in early postnatal cortex, we chose a neuropharmacological approach, since similar procedures employed elsewhere have proved successful in studying intracortical inhibition in the mature visual (Sillito, 1975a, b) and somatosensory (Dykes et al., 1984; Hicks and Dykes, 1983) cortex. In particular, we asked if and to what extent, in early postnatal cortex, functional properties of single neurons, such as orientation and direction selectivity, as well as spatial structure of 
receptive fields, are attributable to an active, intracortical inhibitory mechanism employing GABA.

\section{Materials and Methods}

A detailed description of the methods used has been published elsewhere (Albus and Wolf, 1984); thus, only a short summary follows. Additional procedures not used in the previous study are described in greater detail. The experiments were performed on 18 kittens, ranging in age from 11 to $28 \mathrm{~d}$. As anesthesia, kittens received an initial dose of sodium pentobarbital intraperitoneally $(40 \mathrm{mg} / \mathrm{kg}$ body wt). After muscular relaxation was induced by gallamine triethiodide ( $4-6 \mathrm{mg}$, i.v.), the animals were ventilated with a mixture of $67 \% \mathrm{~N}_{2} \mathrm{O}, 30 \% \mathrm{O}_{2}$, and $3 \% \mathrm{CO}_{2}$. Throughout the experiment, a cocktail mixture of sodium pentobarbital $(2 \mathrm{mg} / \mathrm{kg} / \mathrm{hr})$, gallamine triethiodide $(15 \mathrm{mg} / \mathrm{kg} / \mathrm{hr})$, prednisolone $(0.6$ $\mathrm{mg} / \mathrm{hr}$ ) and levulose $(100 \mathrm{mg} / \mathrm{hr})$ in Ringer's solution was given intravenously at an infusion rate of $1.2-3.0 \mathrm{ml} / \mathrm{hr}$. End-expiratory $\mathrm{CO}_{2}$ and body temperature were continuously controlled and maintained at physiological levels. After retraction of the nictitating membranes with NeoSynephrine and dilation of the pupils with atropine, the kitten was mounted in a stereotaxic head-holder frame (see Horsley and Clarke, 1908) by means of a metal bar fixed to the skull with dental acrylic. A small opening was made above the visual cortex (stereotaxic coordinates A4 to P1 and L0 to L5) which, after introduction of the electrode assembly, was covered with a 4\% solution of agar in Ringer's solution.

Multibarrel electrode arrays containing either 5 or 7 pipette channels were prepared as described previously (Hicks and Guedes, 1983), with the exception that the extracellular recordings of neuronal discharges were made through glass-insulated tungsten electrodes affixed in parallel fashion by a light-curing bonding compound. These recording electrodes were designed so as to yield impedances of 7-11 $\mathrm{M} \Omega$ at $1 \mathrm{kHz} \mathrm{AC}$, and exhibited $2-4-\mu \mathrm{m}$-diameter tips where they extended beyond the insulation (4-6 $\mu \mathrm{m}$ exposure). This method permitted recording with a high signal-to-noise ratio, while maximizing the iontophoretic ejection of drugs from relatively large pipette orifices. The distance between the tip of the recording electrode and the multibarrel pipette assembly orifices ranged between 20 and $200 \mu \mathrm{m}$. The micropipette channels contained glass fibers to enable their rapid filling via capillary action immediately before use. When not in use, micropipette assemblies were kept dust-free in a container with their tips immersed in water. The following solutions of drugs were prepared for each experiment: L-glutamic acid (glutamate; $0.5 \mathrm{M}, \mathrm{pH} 8.0$ ), $\gamma$-aminobutyric acid (GABA; 0.5 $\mathrm{M}, \mathrm{pH} 3.5$ ), and bicuculline methiodide (BMI; 5-10 $\mathrm{mm}$ in $165 \mathrm{~mm}$

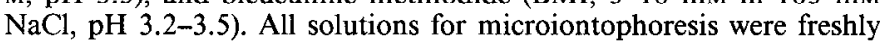
prepared before the experiments, filtered, and kept frozen for subsequent use. Current balancing was occasionally performed but was usually found to be unnecessary; retaining currents of 10-20 nA were routinely employed for each barrel.

Most of the data presented in this study concern the effects of BMI, a pharmacologically specific antagonist of the GABA recognition site of the oligomeric benzodiazepine-GABA receptor-chloride ionophore complex (Nowak et al., 1982; Simmonds, 1982). BMI acts by preventing access of GABA to its receptor and, by itself, is inactive pharmacologically (Heyer et al., 1981), although at relatively high concentrations it does exert a small, direct excitatory action (Straughan et al., 1971). In order to determine a minimally effective dose of BMI but still maintain a subexcitatory level of ejection, we occasionally used the method described by Sillito $(1975 \mathrm{a}, \mathrm{b}, 1984)$ and used in similar experiments elsewhere (Dykes et al., 1984). This procedure involved the ejection of an amount of GABA just sufficient to prevent the light-induced activation of the neuron under study, followed by steadily increasing amounts of BMI until a dose was reached that counteracted the GABA-induced inhibition. This dose of BMI was then taken to be an effective concentration for antagonizing GABA-mediated inhibitory actions upon that particular cell. The amount of ejecting current determined in this way frequently fell within the range of 15-60 nA. Higher doses were often observed to cause direct excitation of the neurons.

The electrode was advanced through the cortical layers at an oblique angle in a rostrocaudal direction. A hand-held projection lamp was used to produce moving and stationary light stimuli of different sizes and shapes (spots, bars, edges) on a dimly illuminated tangent screen (luminance, $1-2 \mathrm{~cd} \mathrm{~m}^{2}$ ) positioned at a distance of $57 \mathrm{~cm}$ from the kitten's eyes. The luminance of the light stimulus was normally 1 and, in some cases, 1.5-2 log units above background. Neurons that were evident only by their spontaneous activity and could not reliably be activated by visual stimulation, or that were silent and produced only injury discharges when impaled by the electrode, were considered to be visually unresponsive.

Upon isolation of units, monocular receptive fields were mapped as "minimum response fields" (Barlow et al., 1967). Orientational and directional asymmetries in the responses to moving and/or stationary bars and edges, as well as velocity response ranges, were then qualitatively determined for the dominant eye. On the basis of the division of the receptive fields into ON and OFF zones, cells were divided into 3 groups: (1) neurons responding exclusively to light $O N$ or to light OFF were classified as unimodal ON or unimodal OFF cells, respectively; (2) neurons having receptive fields with both (or several) ON and OFF zones, generally arranged side by side, were described as bimodal (or multimodal) cells; and (3) if there was no spatial segregation between ON and OFF discharge areas, i.e., if the neuron responded to both phases of a flashing stimulus anywhere in its field, it was classified as an ON-OFF mixed neuron.

For quantitative analysis of response characteristics, we employed a computer-controlled stimulation and spike-acquisition program. With this program, all moving or stationary stimuli could be presented with adjustable directions, velocities of movement, presentation times, and interstimulus intervals. The orientation of an elongated moving stimulus was always orthogonal to the direction of movement. To compensate for response variability, stimuli were interleaved (following the method of Henry et al., 1973). For assessment of orientation specificity, at least 4 different stimulus orientations (i.e., 8 different directions of movement), including the optimal orientation, determined manually, and the orientation orthogonal to it, were presented quasirandomly at least 5 times. The computer was programmed to construct orientation tuning curves with these data. To assess receptive-field structure, stationary stimuli were flashed at adjacent positions within the receptive field and the responses so obtained were averaged over 10 presentations.

For those cells investigated quantitatively, an orientation-specificity index (OSI) was calculated for moving stimuli from the mean response of a cell to stimulation with an optimally oriented slit or bar (optimal response) moved in the preferred direction of movement, or, for stationary stimuli, flashed on and off at the optimal orientation. The mean response (for moving stimuli, the average of responses to both directions of movement) to the same stimulus orthogonally oriented $\left( \pm 15^{\circ}\right)$ to the optimal (nonoptimal response) was also considered through application of the formula

OSI $(\%)=(1-$ nonoptimal response/optimal response $) \times 100$

where response rates have been corrected for spontaneous activity. Cells with an OSI of greater than $90 \%$ were classified as orientation-selective, those with an index in the intermediate range $(50-90 \%)$ as orientationbiased, and cells with an index of less than $50 \%$ as orientation-nonspecific. The same scheme for classification of orientation specificity was employed by Bonds (1979).

Direction specificity was defined in relation to the response in the preferred and nonpreferred directions for an optimally oriented slit. A direction-specificity index (DSI) was calculated by applying the same formula used for computation of the OSI and defined 3 groups: directionselective (DSI $>90 \%)$, direction-biased $(50-90 \%)$, and direction-nonspecific $(<50 \%)$. On completion of the expcriments, the kitten was administered an overdose of sodium pentobarbital and perfused transcardially with a buffered solution of $4 \%$ formaldehyde and $2 \%$ glutaraldehyde. Blocks of the occipital cortex were cut coronally on a freezing microtome and, in some cases, in an oblique plane parallel to the electrode track. After the sections were stained with thionine, the electrode tracks were reconstructed from electrolytic lesions that had been made at intervals of 1-2 mm during retraction of the electrode (4-6 $\mu \mathrm{A}$ for $10 \mathrm{sec}$, electrode negative) and from other landmarks, such as entry into and exit from the white matter. The area 17 and 18 border and laminar positions of the cells were then determined by the criteria of Otsuka and Hassler (1962), and the locations of cells interpolated onto the reconstructed tracks.

\section{Results}

Receptive-field properties without drug administration

Action potentials of 203 neurons in the striate cortex were recorded extracellularly. Of these 203 neurons, 46 were recorded during the second postnatal week, 52 during the third week, and 105 during the fourth postnatal week. The proportion of neurons 
Table 1. Postnatal development of neuronal function in the kitten's striate cortex

\begin{tabular}{|c|c|c|c|c|c|c|c|c|c|c|c|c|}
\hline \multirow{3}{*}{$\begin{array}{l}\text { Age } \\
\text { (PN } \\
\text { week) }\end{array}$} & \multirow{2}{*}{\multicolumn{3}{|c|}{ Orientation sensitivity }} & \multirow{2}{*}{\multicolumn{3}{|c|}{ Direction sensitivity }} & \multicolumn{5}{|c|}{ Spatial receptive-field properties } & \multirow{3}{*}{$\begin{array}{l}\text { Non- } \\
\text { visual }\end{array}$} \\
\hline & & & & & & & \multirow{2}{*}{$\begin{array}{l}\text { Uni- } \\
\text { modal } \\
\text { ON }\end{array}$} & \multirow{2}{*}{$\begin{array}{l}\text { Uni- } \\
\text { modal } \\
\text { OFF }\end{array}$} & \multirow{2}{*}{$\begin{array}{l}\text { Bimodal } \\
\text { multi- } \\
\text { modal }\end{array}$} & \multirow{2}{*}{$\begin{array}{l}\text { ON- } \\
\text { OFF } \\
\text { mixed }\end{array}$} & \multirow{2}{*}{$\begin{array}{l}\text { Non- } \\
\text { static }\end{array}$} & \\
\hline & $\overline{\mathrm{OS}}$ & $\mathrm{OB}$ & ONS & $\overline{\mathrm{DS}}$ & $\mathrm{DB}$ & $\overline{D N S}$ & & & & & & \\
\hline 2 & 24 & 48 & 28 & 6 & 22 & 72 & 9 & 33 & 24 & 7 & 28 & 15 \\
\hline 3 & 56 & 30 & 14 & 13 & 37 & 50 & 23 & 40 & 17 & 17 & 3 & 13 \\
\hline 4 & 66 & 31 & 3 & 35 & 25 & 40 & 29 & 32 & 14 & 23 & 2 & 8 \\
\hline
\end{tabular}

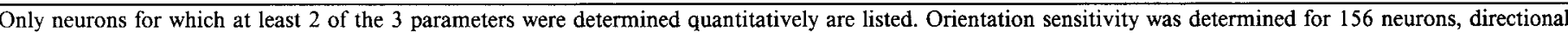

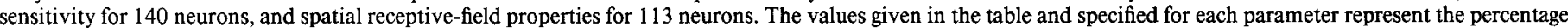
of the total number of cells tested in each age group with respect to that parameter.

that were visually unresponsive or responded in a most erratic way to visual stimulation was $23 / 203(11.3 \%)$ of the total population. The receptive-field parameters mapped for the visually responsive neurons are summarized in Table 1 . Confirming earlier results (Albus and Wolf, 1984; Blakemore and Van Sluyters, 1975; Bonds, 1979; Buisseret and Imbert, 1978; Fregnac and Imbert, 1978), we found that receptive-field characteristics changed considerably during the early postnatal period. The proportions of orientation- and direction-selective neurons increased, whereas the proportions of orientation- and directionnonspecific neurons decreased significantly. The proportions of visually unresponsive neurons also decreased from an average of $15 \%$ during the second postnatal week to $8 \%$ during the fourth week. The large majority of neurons recorded had unimodal receptive fields, i.e., receptive fields that responded only to 1 contrast of the stimulus. Confirming previous results from our laboratory (Albus and Wolf, 1984), during the second postnatal week the majority of these unimodal neurons responded to light OFF. Only during the fourth week did the proportion of ONdominated fields equal that of the OFF-dominated fields. Our findings were also in agreement with earlier observations of a decrease in the proportions of neurons responding exclusively to moving stimuli (i.e., not static; see Table 1), as well as of there being an increase in the proportions of ON-OFF mixed neurons, that is, those that respond equally well to both contrasts of a light stimulus anywhere within their receptive ficlds.

\section{General aspects of the administration of drugs}

In order to analyze the effects of BMI, most experiments have first investigated the neuron without any administration of agonists or antagonists (control), and an orientation tuning curve has been obtained. The neuronal response has then been analyzed during the administration of BMI, which commenced with low ejecting currents of about $10 \mathrm{nA}$. The ejecting current has gradually been increased until an effect on spontaneous and/or light-evoked activity has been noted. If a normally silent unit has become spontaneously active, or if a spontaneously active unit has markedly increased its maintained discharge level during the administration of BMI, the test has been discontinued and a lower dose of BMI chosen for study. Recovery from the effects of BMI has then been observed for at least $20 \mathrm{~min}$, during which time visual stimulation has been continuously performed. When a complete recovery has been obtained, BMI has again been administered in order to investigate the effects of blocking GABA-mediated inhibition on the response to stationary stimulation and on the receptive-field structure. Only after the tests with BMI have been successfully completed has an attempt been made to construct an orientation tuning curve during the administration of glutamate at subthreshold levels for cell excitation. Finally, the effects of GABA on the optimal response have been tested, either alone or in combination with glutamate.

Such schemes had the disadvantage that quantitative results could not be obtained for all cells during the tests with glutamate and GABA. The effects of glutamate were compared in only a third of the cases where BMI was used because of these procedural constraints. The effects of BMI were tested quantitatively on a total of 88 neurons. Nineteen of these were recorded during the second postnatal week, 17 during the third week, and 52 during the fourth. For 56 of the neurons tested quantitatively, their intracortical locations could be determined reliably from the histological sections. All these neurons were recorded from layer III (lower half of the layer) through VI; neuronal activity for visually responsive neurons was not recorded from cells in layer II or from the upper part of layer III. The majority of these 88 neurons responded to visual stimulation reliably and exhibited orientationally and/or directionally selective or biased response properties. Fourteen neurons, however, did not respond at all to visual stimuli or exhibited only irregular, low-frequency responses with a signal-to-noise ratio of less than 2 . Complete orientation tuning curves were compiled before, during, and after administration of BMI for 77 of the 88 neurons. In the 11 remaining cases, pharmacological effects on orientation and direction specificity were assessed from some quantitative measurements and a largely qualitative evaluation. Recovery from BMI was quantitatively examined for 50 neurons. Finally, the effects of BMI on receptive-field structure were examined with static plots from 19 neurons.

Quantitative measurements of the effects of glutamate on orientation or direction specificity have been made for 25 neurons, and of the effects of GABA for 15 neurons.

\section{Effects of BMI on orientation and direction specificity}

The orientation specificity of 45 neurons $(58 \%)$ of the 77 for which complete sets of orientation tuning curves could be constructed decreased following the administration of BMI, whereas orientation specificity did not change significantly in 21 neurons $(28 \%)$. All the remaining 11 neurons (14\%) were either initially unresponsive or responded in an erratic way to visual stimulation. All these visually unresponsive cells became clearly responsive following the administration of BMI, even exhibiting orientation-specific tuning curves during the period of time when the antagonist was being ejected.

Of the 45 neurons that were initially visually responsive and exhibited a decrease of orientation specificity under BMI, 14 $(18 \%)$ became orientation-nonspecific, that is, they lost all orientation tuning (within the limits of the definition; see Materials and Methods). In typical cases (Figs. 1-3), BMI exerted its maximal effects only after prolonged periods of ejection (20-40 min), and the recovery from the effects of BMI also needed quite some time (at least 10-15 min). As demonstrated in Figure 3, in some neurons the reduction in inhibitory processes produced by the antagonist first occurred at the orientation approximately orthogonal to the optimal one. At various subsequent intervals following the initial effect of the drug, orientations next to the formerly optimal one were also affected, resulting in more reg- 

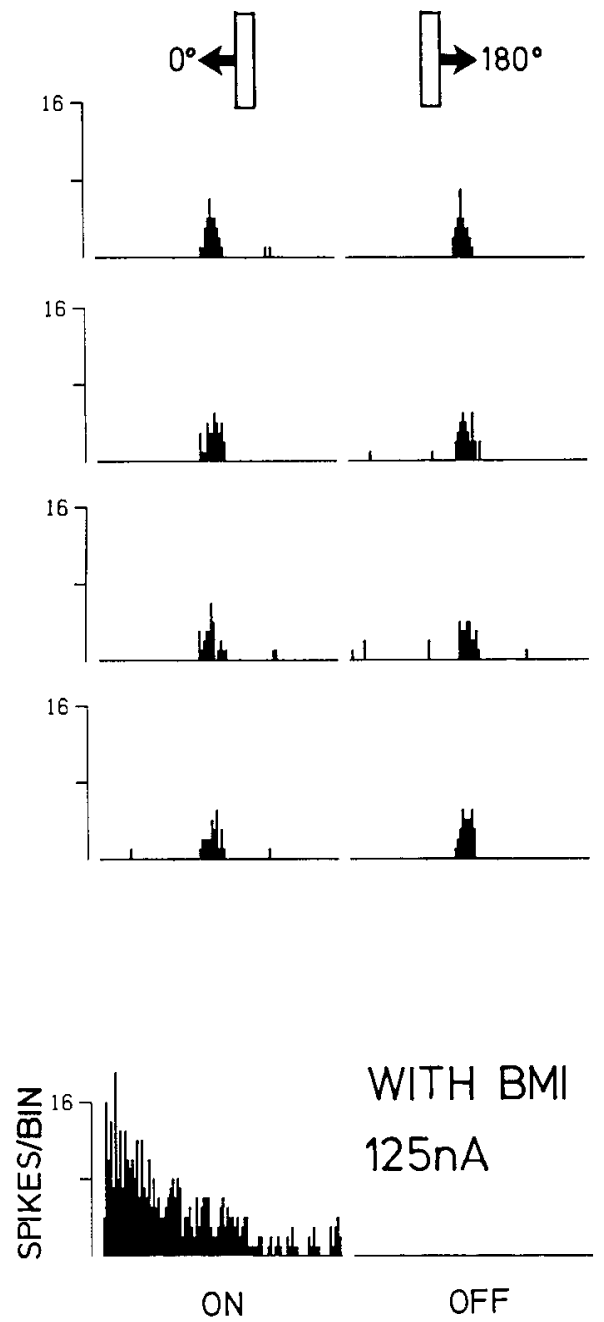
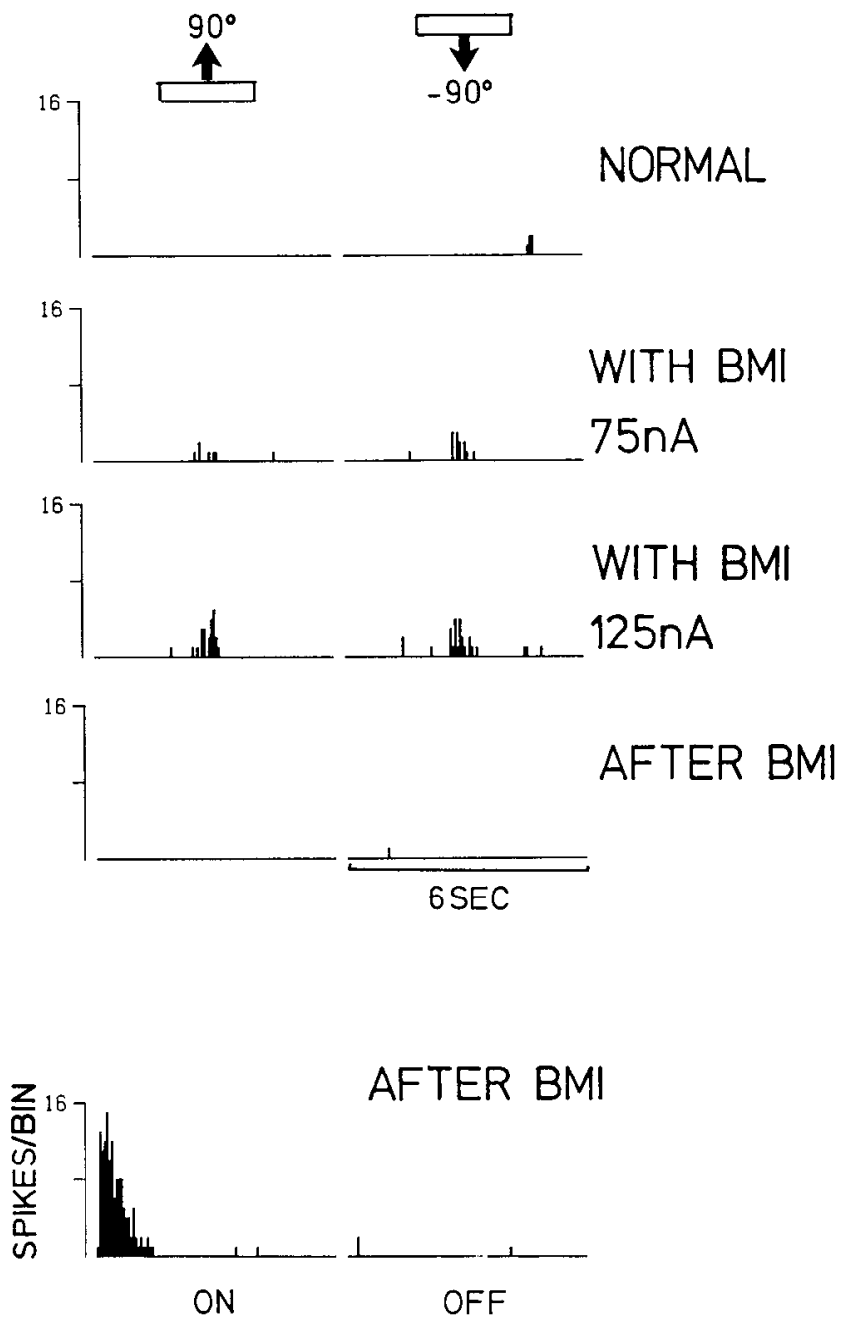

Figure 1. Orientation tuning of an orientation-selective, direction-nonspecific neuron recorded from area 17 in a 26 -d-old kitten before, during, and after microiontophoretic administration of the GABA antagonist, BMI. Single poststimulus time histograms (psths) are reproduced, showing the responses to the optimally (direction $0^{\circ}$ and $180^{\circ}$ ) and nonoptimally (direction $90^{\circ}$ and $-90^{\circ}$ ) oriented light bar moving forwards and backwards across the receptive field. Data were collected 7-14 $\min$ ( $75 \mathrm{nA} / \mathrm{BMI}$ ) and 14-21 min (125 nA/BMI) after the start of BMI administration. Stationary stimulation of the center of the receptive field with the same light bars as used for plotting the orientation tuning during 22-25 min after the start of BMI administration and after BMI resulted in psths shown at the bottom. ON and OFF periods lasted 6 sec each. Unimodal ON neuron, ocular dominance group 1, no histology. Bin widths of psths, $60 \mathrm{msec}$. Light stimuli in this and other neurons tested consisted of light bars $3^{\circ}-15^{\circ}$ long, $0.1^{\circ}-2^{\circ}$ wide, and moving with velocities of $1^{\circ}-10^{\circ} / \mathrm{sec}$. Movement was always perpendicular to bar orientation, and each direction (or position within the receptive field) was tested 3-10 times. In the neuron shown, 12 different movement directions were tested (for orientation tuning curves, see Fig. 2).

ularly formed tuning curves, with elliptical or roundish shapes. Also typical was that in most neurons where BMI caused a transformation of the neuronal responses to the orientationnonspecific category, the tuning curves did not become totally circular. As can be seen in Figures 2 and 3, they retained some asymmetry, the response to the formerly optimal stimulus being somewhat stronger than the response to nonoptimal stimuli. For 31 neurons $(40 \%)$, the decrease in orientation specificity was not complete; thus they still exhibited some orientation preference, even after prolonged administration of BMI. In this group, 23 neurons changed from the orientation-selective class to the orientation-biased class (Fig. 4), whereas the remaining 8 cells did not change their orientation-specificity indices, showing only moderate broadening of their orientation tuning curves. The average increase in halfwidth for all cells of this group was $21^{\circ}$.

The proportions of neurons that changed their orientation specificity following BMI were about the same during the second, the third, and the fourth postnatal weeks. During the second week, however, no orientation-selective neuron was seen to change to orientation-nonspecific. The 5 orientation-selective neurons tested during that early period either became orientation-biased or remained unaffected. For the entire 2-4 week sample, the change in orientation specificity during ejection of BMI was seen in all layers of the striate cortex (see above) and in all neuronal types, as indicated in Table 1 . All types of neurons were affected in about the same proportions. Changes from orientation-selective to orientation-nonspecific, however, were only observed with unimodal and bimodal neurons.

At all postnatal ages we recorded from neurons that remained completely unaffected with respect to their orientation specificity in the presence of BMI. A typical example is shown in Figure 7. Even when subjected to high ejection currents of the antagonist for long periods of time (longer than $30 \mathrm{~min}$ ), these neurons did not demonstrate any change in their orientation tuning curves. Other neurons in the same penetration where these BMI-resistant cells were found exhibited clear-cut effects of the drug on reducing stimulus specificity. For 14 of the neurons that did not 
NORMAL

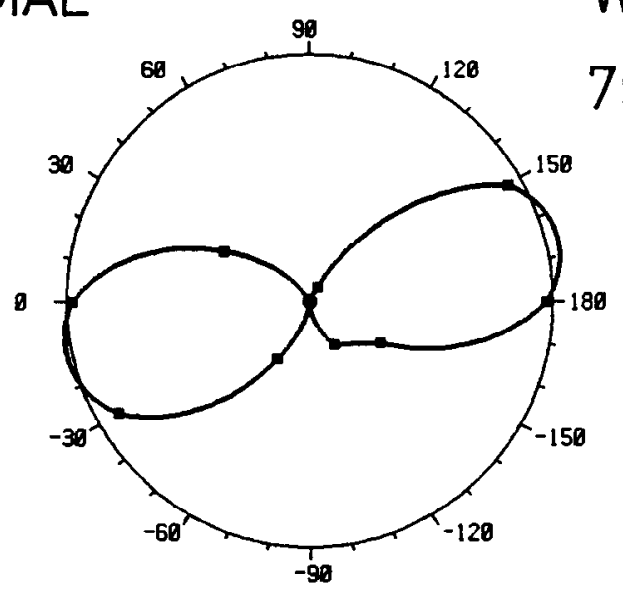

WITH BMI

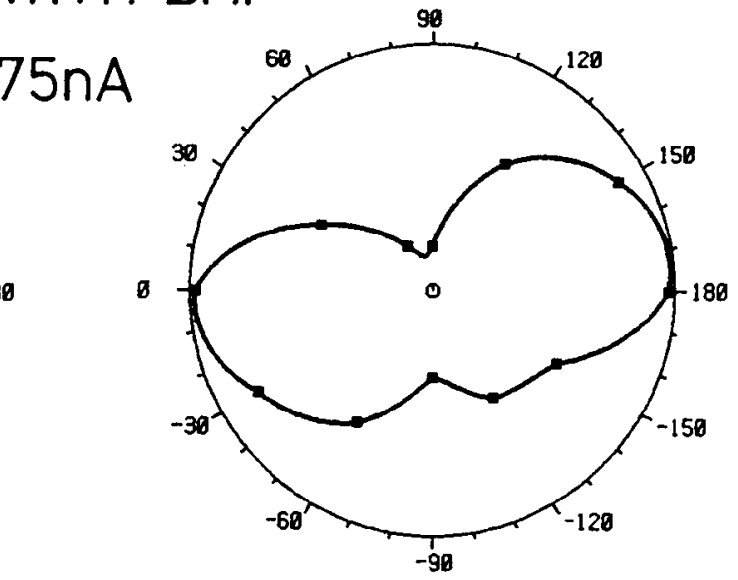

AFTER BMI

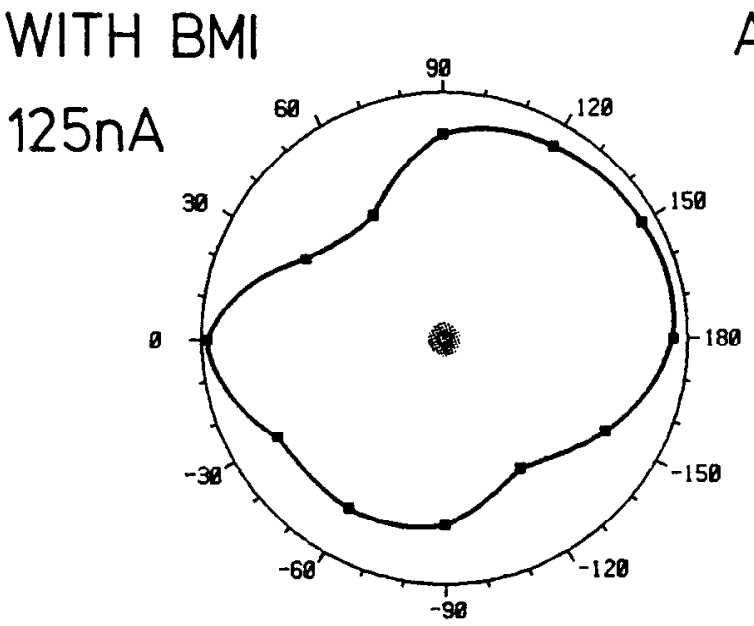

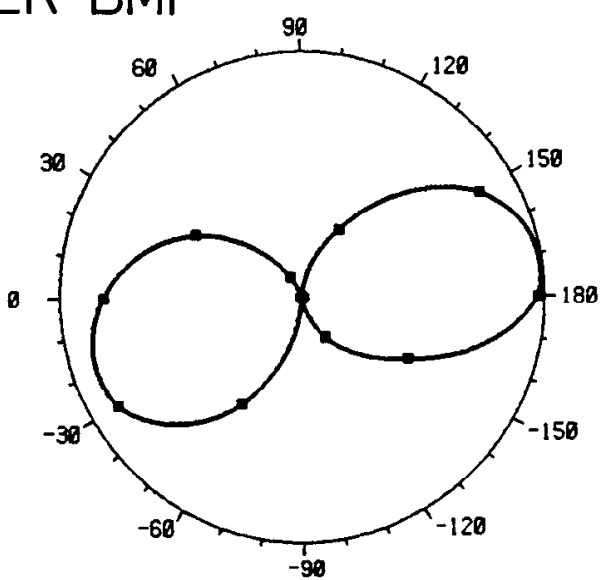

Figure 2. Orientation tuning of an orientation-selective, direction-nonspecific neuron from area 17 in a 26 -d-old kitten before, during, and after microiontophoretic administration of GABA antagonist, BMI. Same neuron as in Figure 1 . On the basis of the average number of action potentials in the response profiles of the psths as shown in Figure 1, responses were normalized and plotted as polar diagrams, as seen in this figure. Curves are interpolated between data points ( 2 on each side, parabolic interpolation of fourth power) such that the optimal response could come to lie between points (see Normal and $A f t e r B M I$ ). The level of spontaneous activity is given by the radius of a shaded area in the center of the polar diagrams. Orientation selectivity index (OSI): Normal, 96.4; with BMI, 75 nA, 73.7; with BMI, $125 \mathrm{nA}, 19.8$; after BMI, 100.0. Maximum discharges (spikes/sec): Normal, 5.8; with BMI, 75 nA, 6.1; with BMI, 125 nA, 5.0; after BMI, 5.8.

undergo changes in orientation specificity following the ejection of BMI, their receptive-field structures could be studied in detail and their intracortical locations could be determined. They were located in layers IV and VI and had unimodal, bimodal or ONOFF mixed fields; i.e., all receptive-field types were affected, with the exception of the neurons that were driven exclusively by moving stimuli. Interestingly, only 3 of the 7 directionally specific neurons in this group exhibited a reduction in directional specificity. The remaining neurons in which specific response properties (orientation selectivity or both orientation and direction selectivity) remained unchanged, however, did show other effects of BMI, such as changes in the spatial arrangement of receptive fields, or increases in visually evoked response.

Forty-one direction-specific neurons that were also either orientation-selective or orientation-biased were tested with BMI. The majority of these $(56 \%)$ became direction-nonspecific following the administration of the drug, 17\% changed from direction-selective to direction-biased, and $27 \%$ remained unchanged. Changes in direction specificity occurred at all postnatal ages and were observed for all cell types and throughout layers III-VI. Of the 11 neurons that were not influenced by BMI in their directional specificity, 6 could be assigned to cortical layers; these neurons were all located in layer VI and represented all receptive-field types seen in the immature striate cortex. It is worth noting that only 4 of the 11 neurons with unchanged direction specificity exhibited a reduction of orientation specificity during the ejection of BMI (Fig. 4), although all showed an increase in the magnitude of their discharges to visual stimuli.

\section{Effects of glutamate on neuronal response specificity}

It was possible to construct complete orientation tuning curves for 7 visually responsive neurons during the microiontophoretic administration of glutamate. In all cases, glutamate ejection led to an increase in spontaneous discharges, as did the administration of BMI when presented at higher doses. The testing of glutamate, however, proved much more difficult in neonatal animals than, for example, in adult cortex (Dykes et al., 1984; Hicks and Guedes, 1983), as it was rarely possible to adjust the 

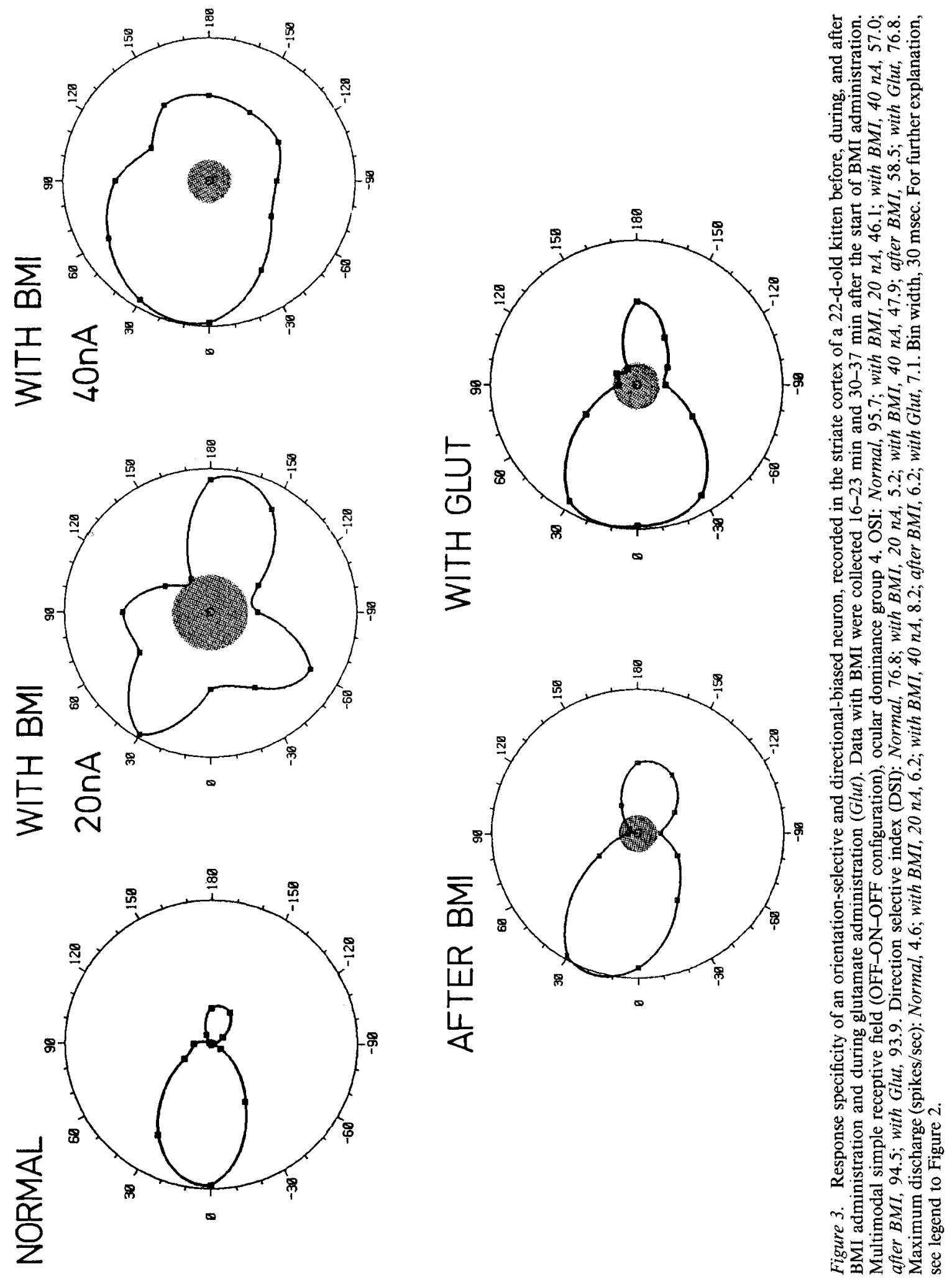
NORMAL

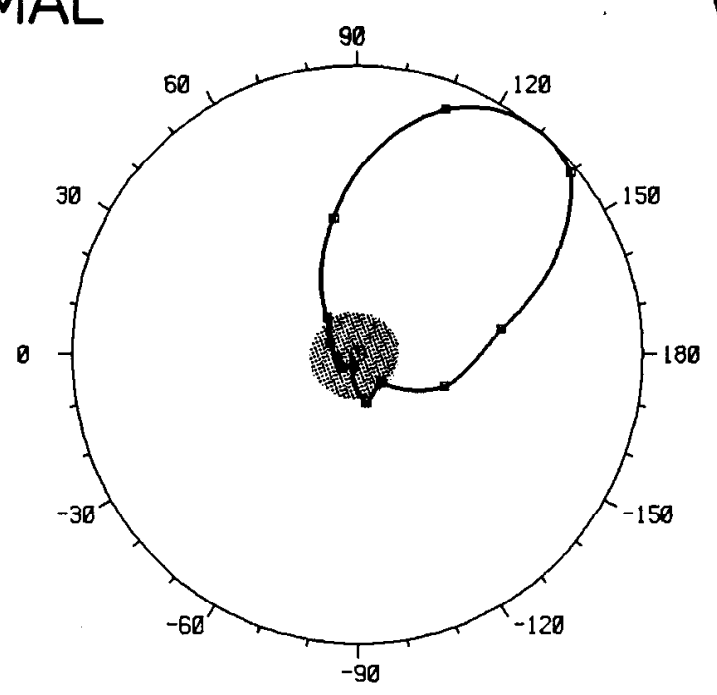

\section{WITH BMI}

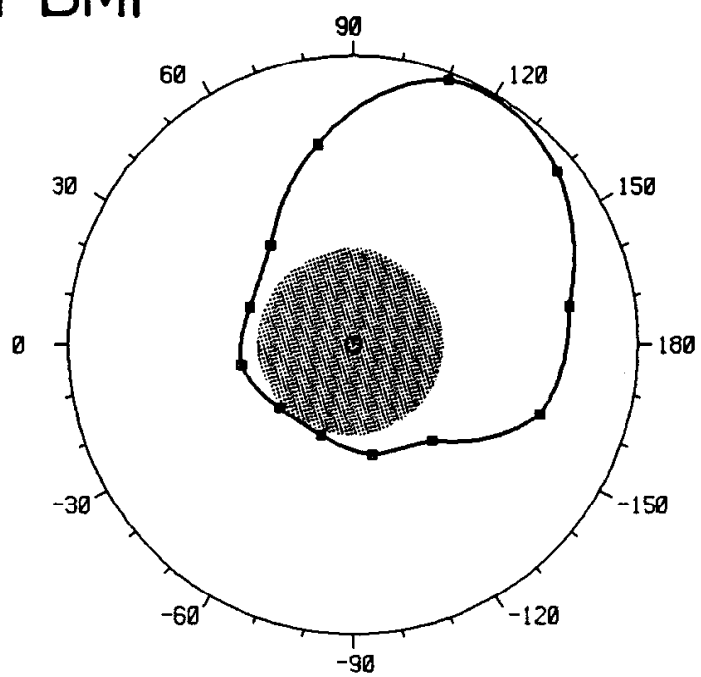

WITH GLUT

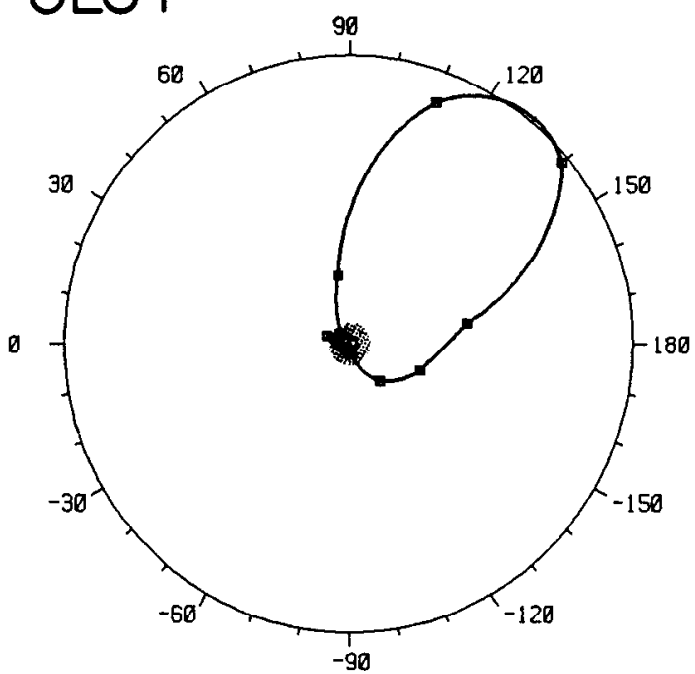

Figure 4. Response specificity of an orientation- and direction-selective neuron recorded in the striate cortex of a 23-d-old kitten before, during, and after the administration of BMI and during the administration of Glut. Data with BMI were collected 4-13 min after the start of BMI administration (ejection current, $20 \mathrm{nA}$ ). With Glut, ejection current started with $20 \mathrm{nA}$ and was increased to $60 \mathrm{nA}$. Complex receptive field, ocular dominance group 3, layer VI. OSI: Normal, 98.2; with BMI, $20 \mathrm{nA}, 71.6$; after BMI, $20 \mathrm{nA}, 92.0$; with Glut, 93.1. DSI: Normal, 100.0; with BMI, $20 \mathrm{nA}$, 97.8; after BMI, $20 \mathrm{nA}$, 98.5; with Glut, 100.0. Maximum discharge (spikes/sec): Normal, 9.5; with BMI, 20 nA, 19.0; after BMI, 20 $n A, 6.5$; with Glut, 6.8. Responses are displayed as polar diagrams. For further explanation, see legend to Figure 2.

ejection current to a level at which an effect of the drug on response specificity could be measured without the neuron's spontaneous activity obscuring its visually elicited activity. For many neurons, the ejection of glutamate, even at very small doses, soon led to a depolarization block. This was especially the case with neurons from the more immature cortices of animals studied during the second and third postnatal weeks. The effects of glutamate on orientation and direction specificity were clearly different from those of BMI. In 5 cases (of the 7 investigated), glutamate did not induce changes in orientation or direction specificity, as did BMI for the same neurons (Figs. 3 and 4 ). In the remaining cases, glutamate was difficult to adjust at threshold so that a considerable increase in spontaneous activity was necessarily produced. This resulted in a low response- to-noise ratio $(<2.5)$ that was, in fact, never observed during the administration of BMI, even at higher ejection currents.

\section{Effects of BMI on receptive-field structure}

It has becn reportcd (Sillito, 1975b; Sillito et al., 1980) that in simple neurons of layer IV of the adult striate cortex, the elimination of orientation sensitivity by blocking GABA-mediated inhibition is accompanied by a loss of the separation between the excitatory $\mathrm{ON}$ and $\mathrm{OFF}$ subregions within the receptive field. Because of this observation, it was expected that significant changes of the spatial structure of bimodal or multimodal receptive fields would be found in immature visual cortex when the cells' orientation specificity was significantly altered following the administration of BMI. Surprisingly, however, such a 

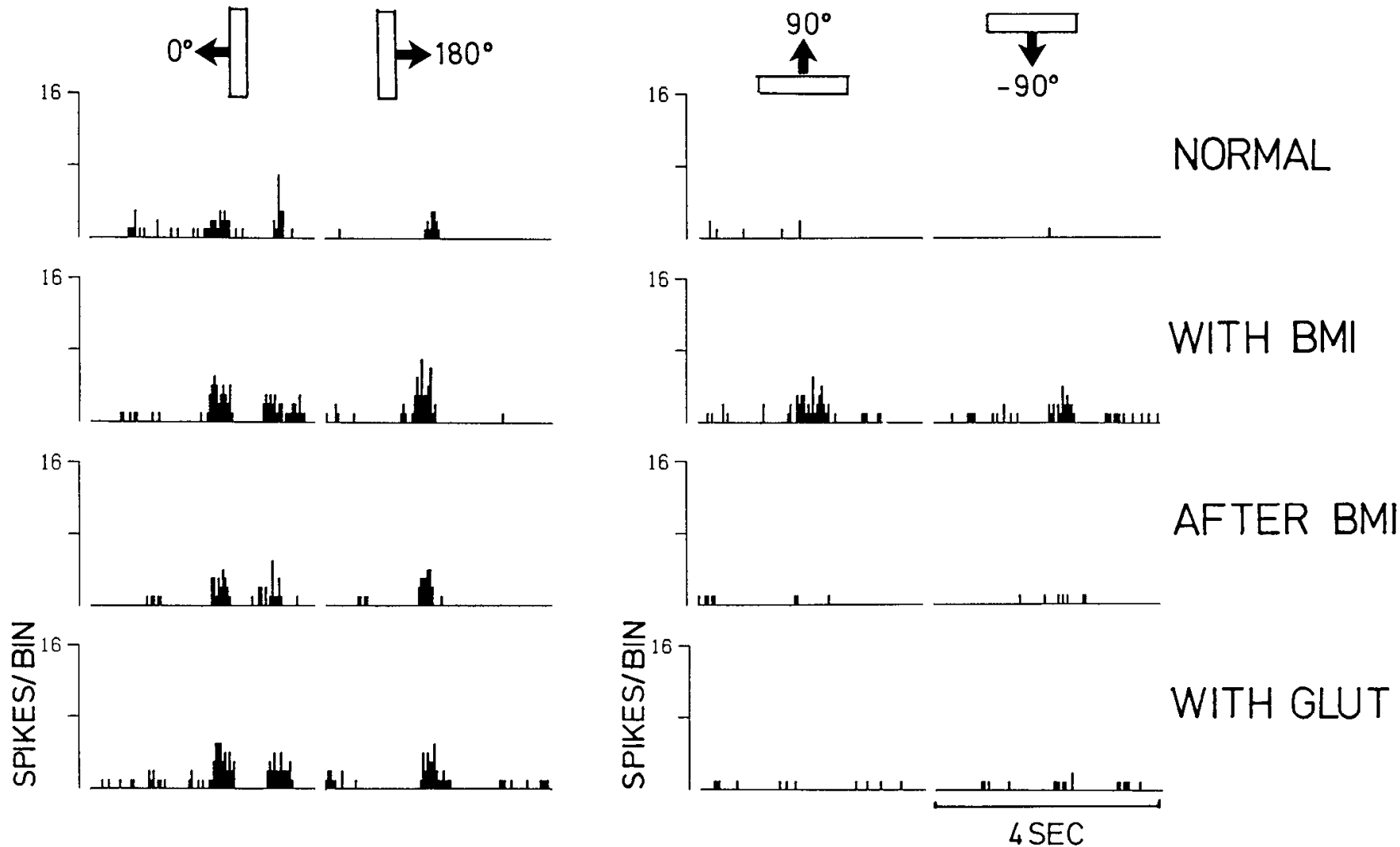

Figure 5. Response specificity of an orientation-selective and directional-biased neuron, recorded in the striate cortex of a $22-\mathrm{d}$ old kitten before, during, and after BMI administration. Same neuron as in Figure 3. Responses are displayed as psths and show the responses to the optimally (direction $0^{\circ}$ and $180^{\circ}$ ) and nonoptimally oriented (direction $90^{\circ}$ and $-90^{\circ}$ ) light bar moving forwards and backwards across the receptive field Bin width, 40 msec.

straightforward correlation was found neither in bimodal or multimodal receptive fields nor in unimodal or mixed receptive fields.

Eighteen neurons (located in layer IV or VI) were studied quantitatively both with moving and stationary stimuli before, during, and after the ejection of BMI. The sample consisted of 6 bimodal or multimodal (i.e., simple) neurons, 7 unimodal, and 5 mixed receptive-field types. For the simple receptive fields, in 2 cases the OSIs decreased while the ON and OFF subregions remained separated. For example, before BMI, the receptive field of the neuron shown in Figure 5 consisted of a central ON zone flanked by 2 OFF zones. As seen in the normal poststimulus time histogram, the optimally oriented moving stimulus entering the receptive field (direction 0) first elicited an OFF response from its trailing edge; then an $\mathrm{ON}$ response occurred from the leading edge; then again an OFF response reappeared from the trailing cdgc. This arrangement remained rather stable throughout BMI iontophoresis, after recovery from the effects of BMI, and during glutamate ejection, with only a slight increase in the widths of the subareas of the receptive field being observed. In spite of this constancy in the spatial arrangement of subareas, orientation sensitivity was nearly abolished with BMI (see Fig. 3). Independence of BMI effects from orientation sensitivity and the arrangement of the excitatory subregions in simple cells is also illustrated in the case shown in Figure 6. The receptive field of this neuron had a central ON region, flanked by 2 weak OFF regions. Although during BMI the OFF response and $1 \mathrm{ON}$ response increased in width and height, both response peaks were still clearly separated from each other. With a further 3 cells of the bimodal group in which the orientation selectivity indices remained unchanged (showing only a moderate increase in the widths of the tuning curve, or no effect at all during BMI), the separation of ON-OFF areas was either totally lost (Fig. 7) or remained constant. In the 1 remaining case, neither the orientation selectivity nor the spatial arrangement of the receptive field changed.

The functional independence of the effects of BMI from orientation sensitivity and spatial receptive-field characteristics was also observed in the group of neurons possessing unimodal receptive fields. The cell shown in Figures 1 and 2 retained its unimodality under BMI, while its orientation selectivity was completely lost (see Fig. 1, bottom). Another cell whose orientation sensitivity remained unchanged developed a bimodal arrangement of its receptive field, showing a moderate overlap between the ON and OFF areas. In a third neuron, neither unimodality nor orientation sensitivity changed during BMI ejection. In the 4 remaining cases, the reduction of orientation sclectivity was accompanied by a change in the spatial composition of the receptive field. The latter changes, however, were rather moderate; in 2 of these cases (one of which is shown in Fig. 8) a subdominant OFF response was added to a dominant ON response, suggesting the appearance of a bimodal field. In the remaining cases, formerly unimodal OFF receptive ficlds were transformed into the ON-OFF mixed type. The 4 cells exhibiting mixed receptive fields preserved their basic spatial structure regardless of whether orientation sensitivity remained constant ( 1 case) or was reduced ( 3 cases). However, changes in the balance between $O N$ and OFF components were observed in all of these cases. There was also no clear correlation between the effects of BMI on direction selectivity and on the spatial structure of the receptive field. Reduction or elimination of direction selectivity was combined either with no change in 
NORMAL

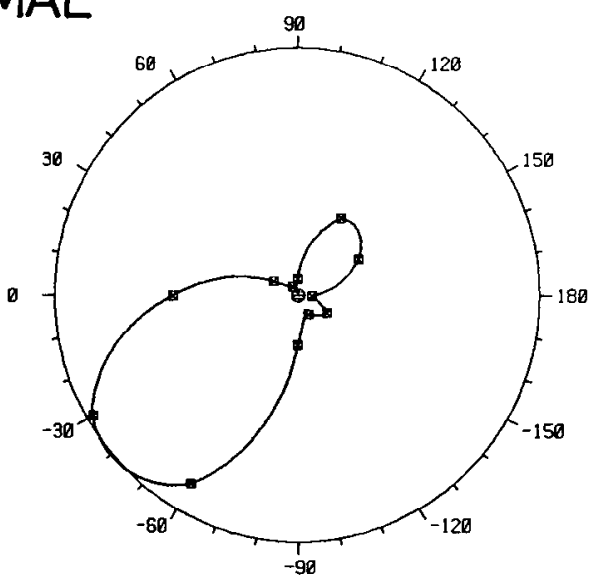

\section{WITH BMI}

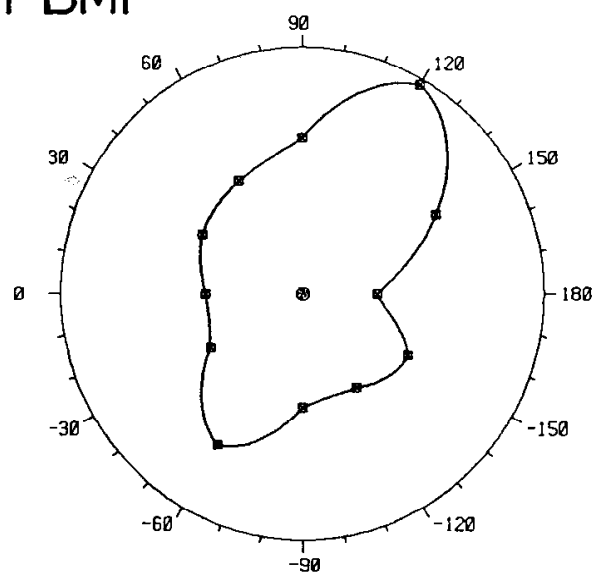

$0---0$ ON

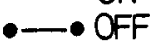

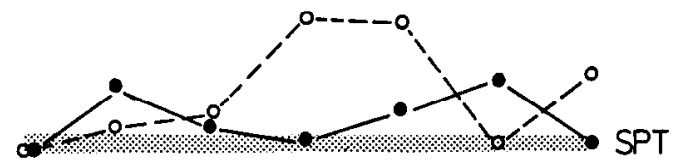

\begin{tabular}{lllllll}
\hline & 1 & 1 & 1 & 1 & 3
\end{tabular}

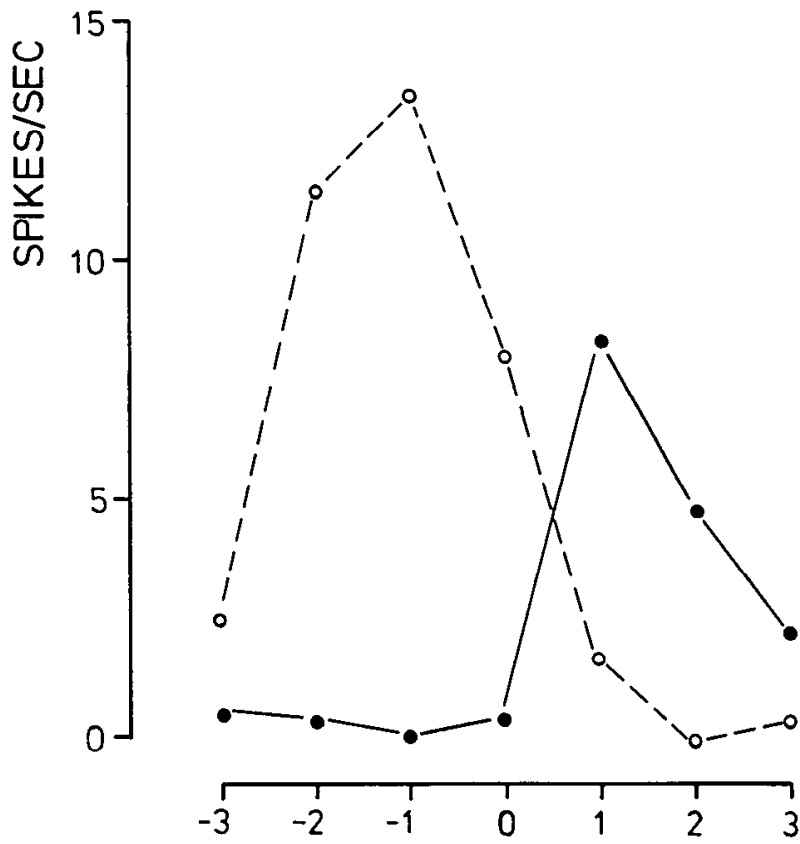

DISTANCE FROM RF-CENTRE(DEGREE)

Figure 6. Response specificity and receptive-field structure of an orientation-selective and directional-biased neuron, recorded in the striate cortex of a 22-d-old kitten before, during, and after BMI administration. Data with BMI were collected 10-18 min after the start of BMI administration (ejection current, $30 \mathrm{nA}$ ). Trimodal (i.e., simple) receptive field, ocular dominance group 4. OSI: Normal. 95.6; with BMI, 30 nA, 50.6. DSI: Normal, 68.1; with BMI, $30 \mathrm{nA}, 27.9$. Maximum discharge to moving stimuli (spikes/sec): Normal, 14.2; with BMI, $30 \mathrm{nA}, 10.6$. Responses to moving stimuli are displayed as polar diagrams. The receptive-field type is revealed by plotting the mean responses to stationary stimulation as a function of stimulus position within the field (right-hand side). For further explanation, see legend to Figure 2.

spatial receptive-field structure (Figs. 3 and 5) or a moderate (Fig. 6) to strong change in receptive-field structure. In 1 further neuron (Fig. 7), the direction selectivity remained essentially unchanged during BMI iontophoresis, whereas the receptive field was transformed to ON-OFF mixed from the bimodal.

These results and those presented above indicate that the synaptic organization responsible for the various functional parameters tested (orientation sensitivity, direction sensitivity, spatial receptive-field structure) is unlikely to be the same. This means either that synaptic transmitters other than GABA are also active indicating receptive-field properties or that GABA exerts its effect on the various functional specifications at different synaptic sites (see Discussion).

\section{Pharmacological effects on visually unresponsive neurons}

Recordings have been made from a number of neurons, especially in the younger kittens, which either did not respond to any visual stimulus at all or responded only in an extremely erratic way to visual stimulation. In the latter group, the signalto-noise ratio was generally less than 2 , even with optimal stimuli, and maximal responses did not exceed 0.5 spikes/sec. Initially, glutamate was tested on these neurons, and in many cases this led to an increase of visually evoked activity. These observations were mainly qualitative, however. To answer the question, Was the poor responsiveness of these neurons to visual stimuli caused by a weak excitatory drive, or were the neurons dominated by intracortical inhibitory influences (or, if both these mechanisms were responsible, how can one differentiate between them), quantitative tests were attempted with BMI as well as with glutamate.

The effects of BMI on the activation of a total of 14 neurons that were initially visually unresponsive were assessed quantitatively. As expected on the basis of the idea that visually unresponsive neurons in immature cortex might be dominated by inhibitory influences, in all cases the ejection of the drug caused a significant increase in the responsiveness to visual stimulation. 
NORMAL

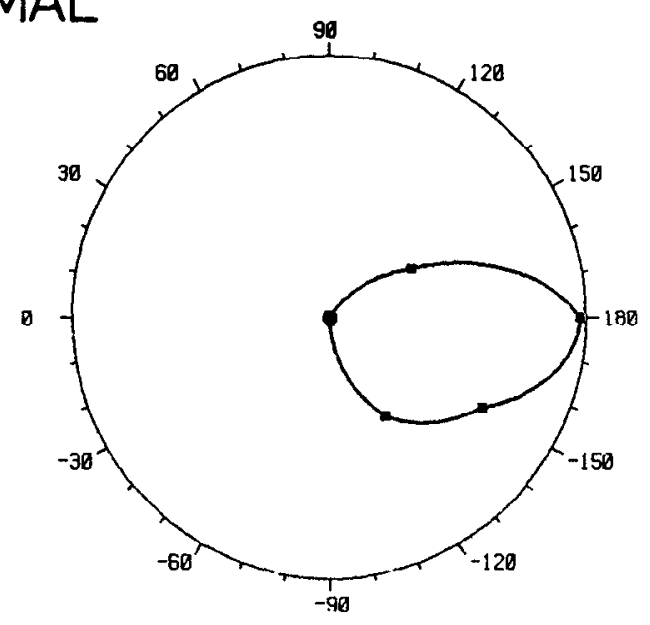

\section{WITH BMI}

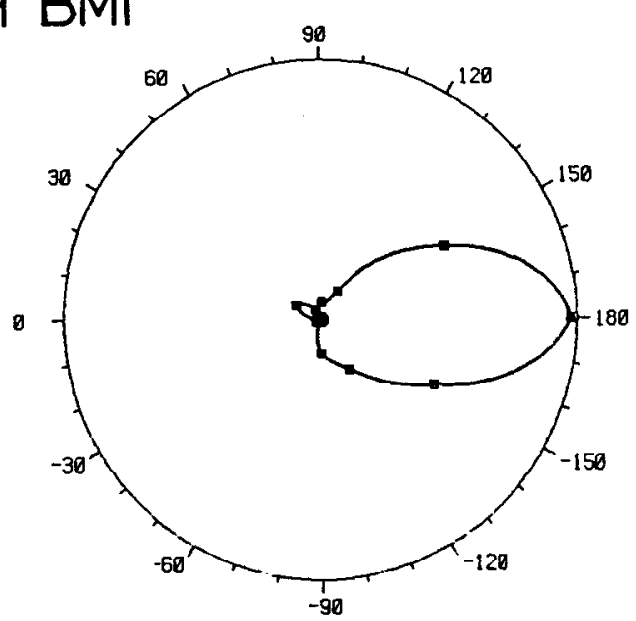

\section{AFTER BMI}

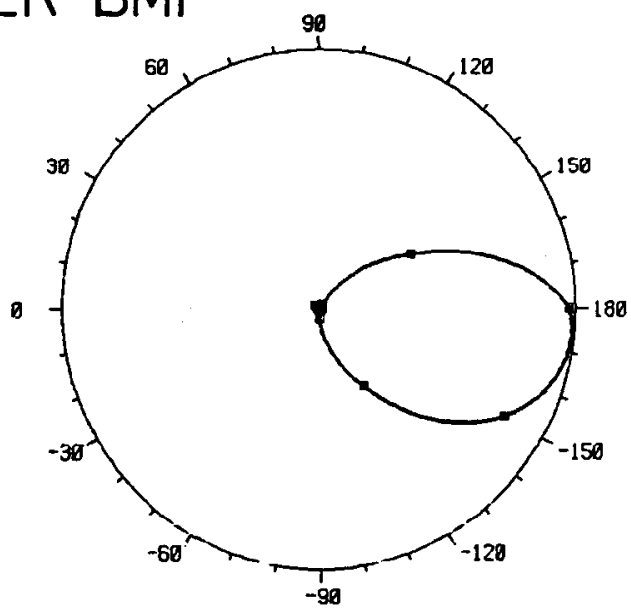

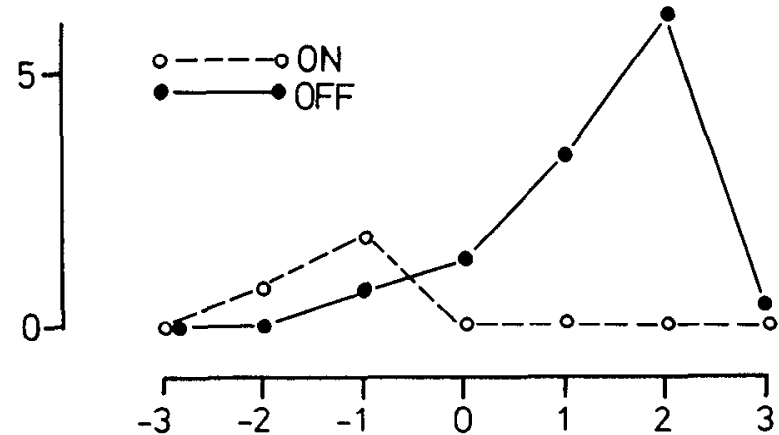
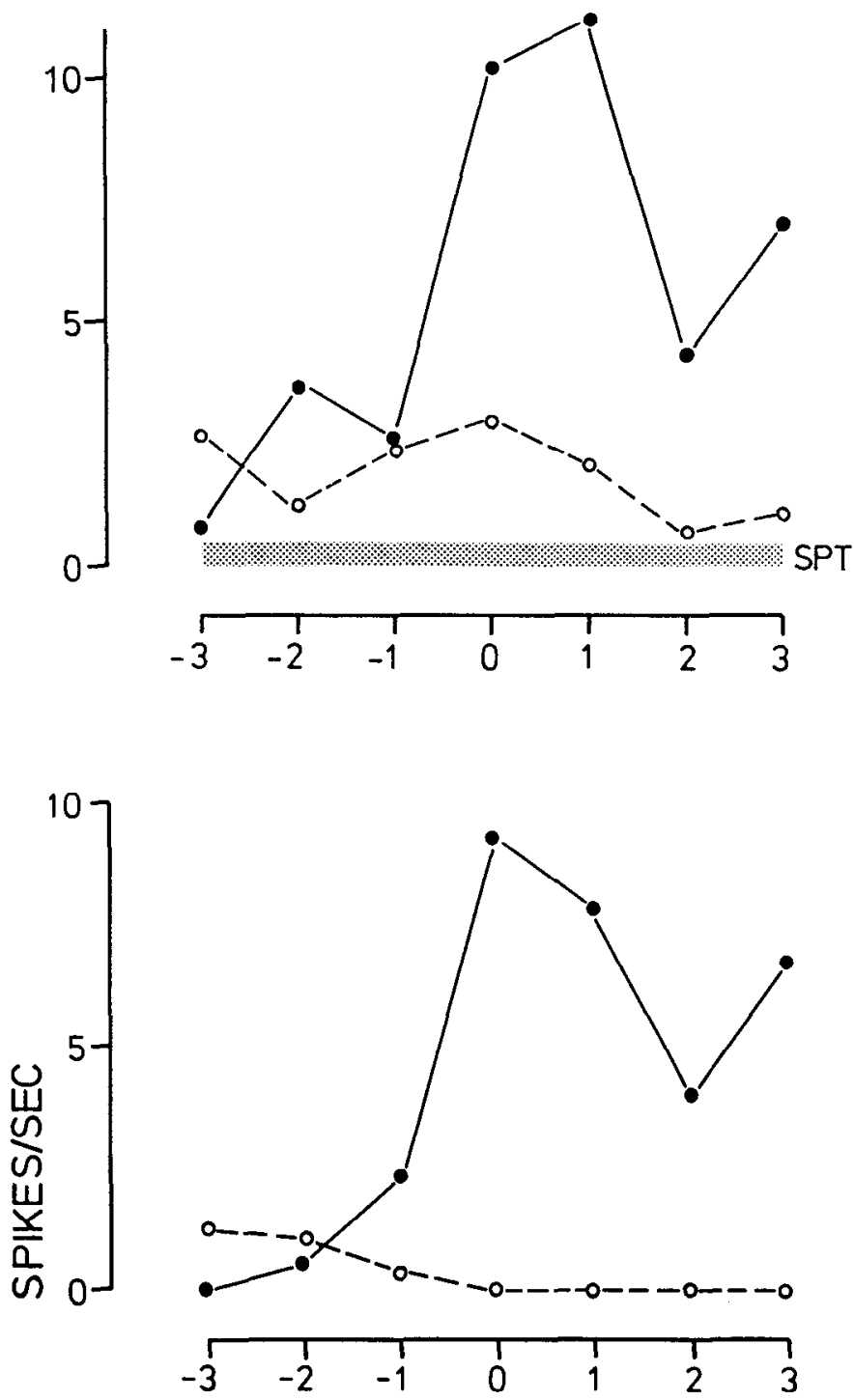

DISTANCE FROM RF-CENTRE(DEGREE)

Figure 7. Receptive-field structure of an orientation- and direction-selective neuron recorded in the striate cortex of a 24-d-old kitten before, during, and after BMI administration. Data with BMI were collected 32-35 min (stationary) and 36-45 min (moving) after the start of BMI administration (ejection current during this period, increasing from 35 to $60 \mathrm{nA}$ ). Bimodal (i.e., simple) receptive field, ocular dominance group 1, layer VI. OSI: Normal, 99.3; with BMI, 91.5; after BMI, 99.4. DSI: Normal, 100.0; with BMI, 100.0; after BMI, 99.4. Maximum discharge (spikes/sec): Normal, 21.0; with BMI, 23.2; after BMI, 30.2. Responses are displayed as polar diagrams. The receptive-field type is revealed by plotting the mean response to stationary stimulation as a function of stimulus position within the receptive field (right-hand side). For further explanation, see legend to Figure 2. 
NORMAL

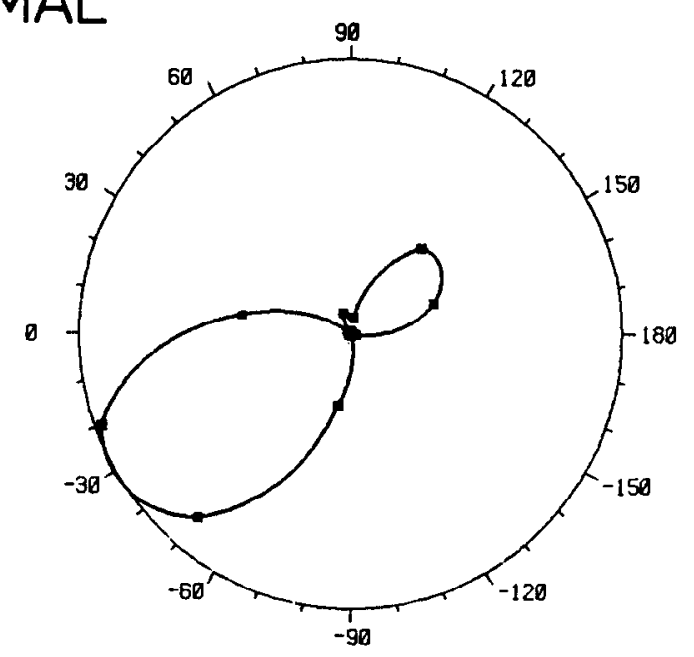

\section{WITH BMI}

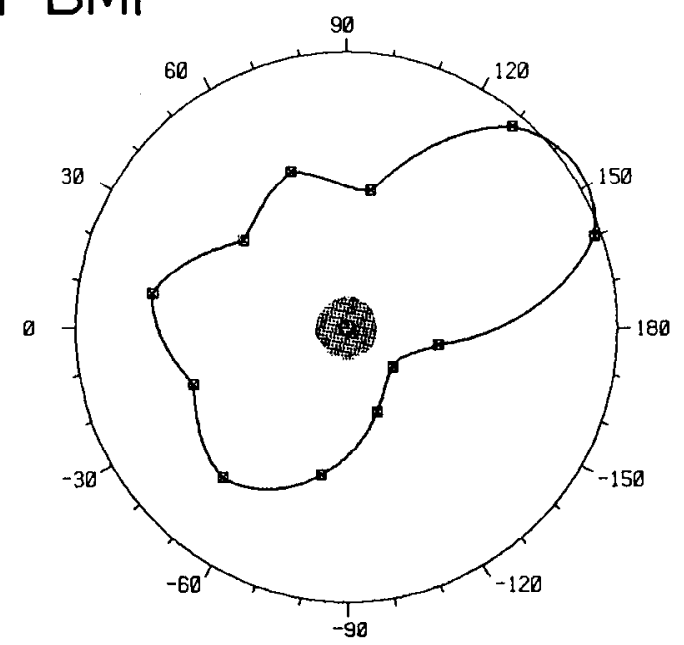

\section{AFTER BMI}

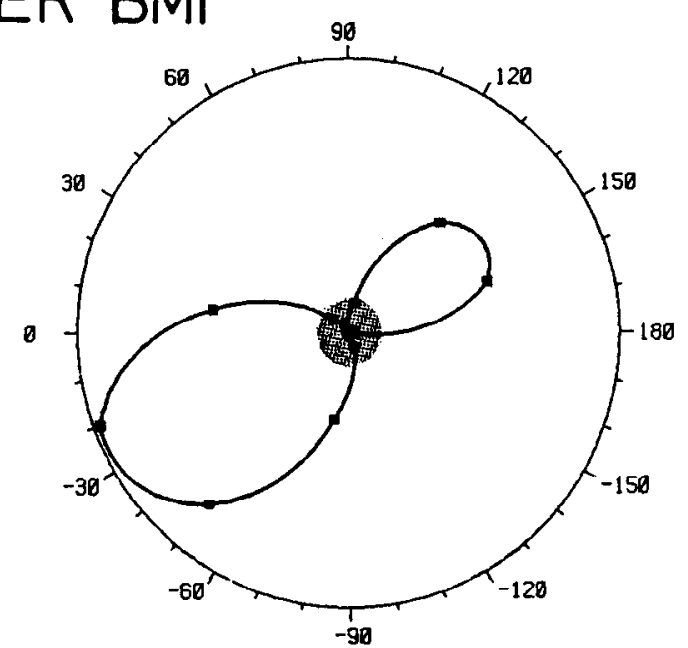

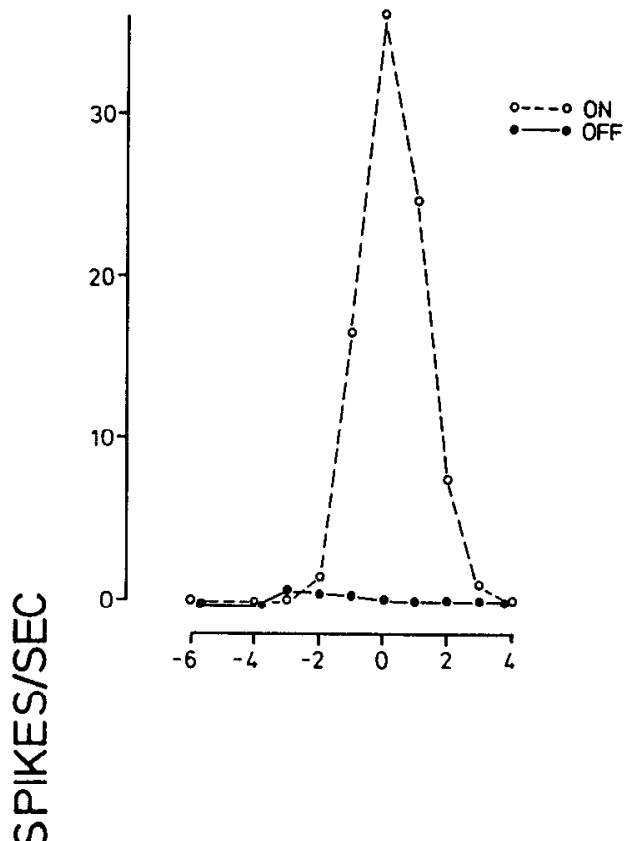

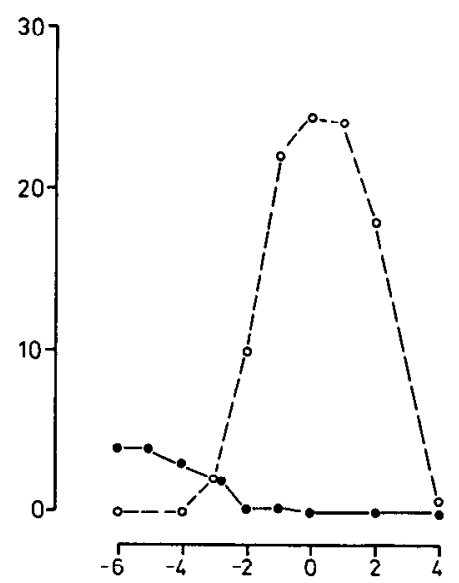

DISTANCE FROM RFCENTRE(DEGREE)

Figure 8. Response specificity and receptive-field structure of an orientation-selective and directional-biased neuron, recorded in the striate cortex of a 24-d-old kitten before, during, and after BMI administration. Data with BMI were collected 9-12 min (moving) and 15-18 min (stationary) after the start of BMI administration (ejection current, $35 \mathrm{nA}$ ). Unimodal ON response, ocular dominance group 5, layer IVc. OSI: Normal, 100.0; with BMI, 68.3; after BMI, 100.0. DSI: Normal, 63.9; with BMI, 41.5; after BMI, 47.5. Maximal discharge (spikes/sec): Normal, 15.2; with BMI, 17.2; after $B M I, 15.6$. Responses to moving stimuli are displayed as polar diagrams. The receptive-field type is revealed by plotting mean responses to stationary stimulation as a function of stimulus position within the field (right-hand side). For further explanations, see legend to Figure 2. 

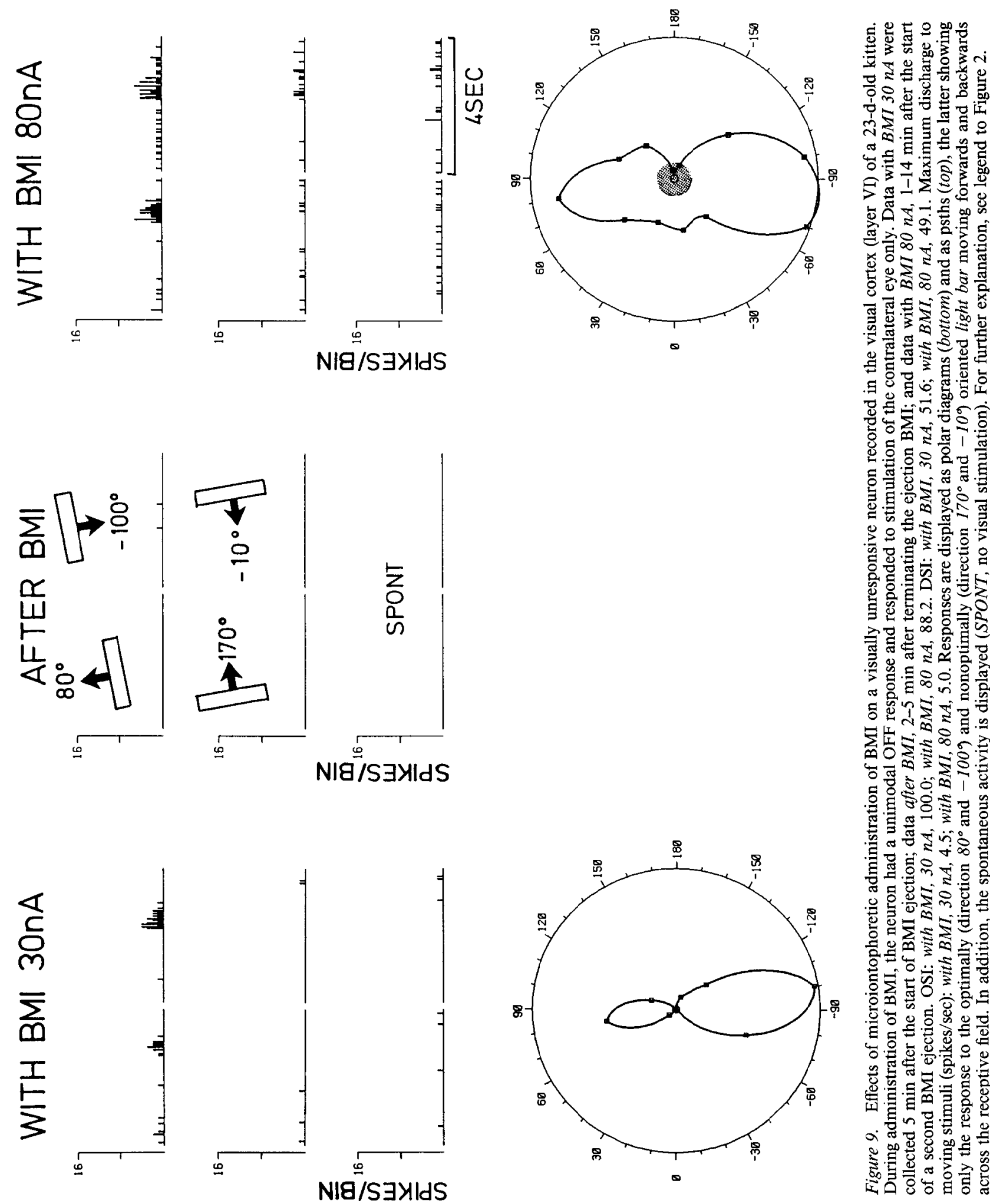

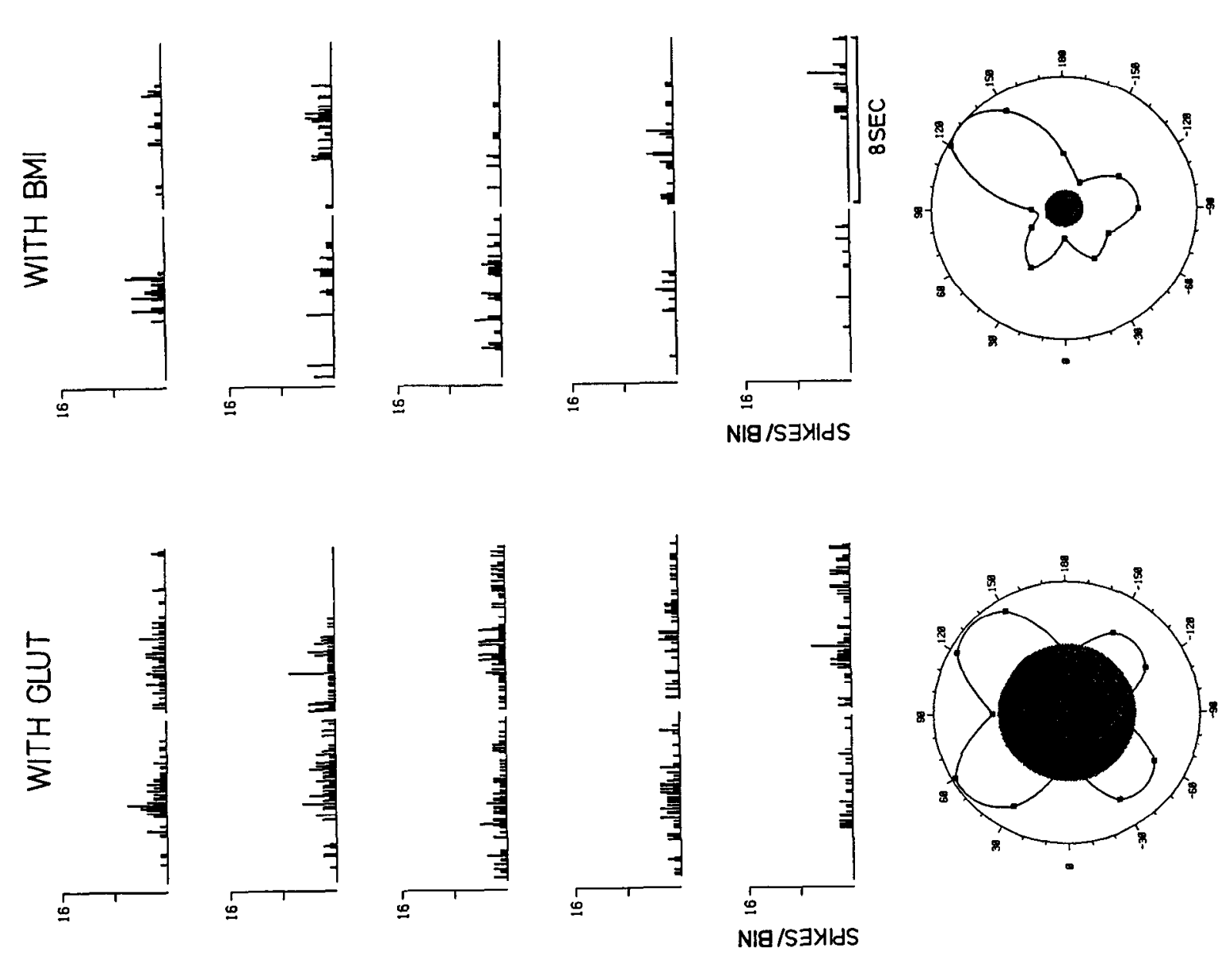

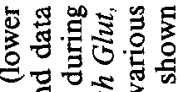

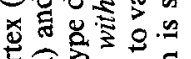

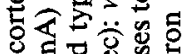

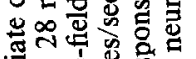

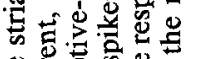

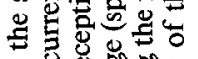

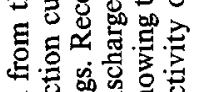

马ㄹ⿺ㄹ

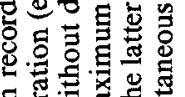

돈

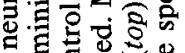

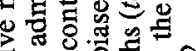

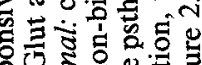

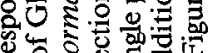
之. 혀의

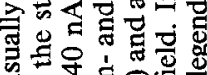

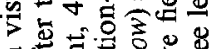

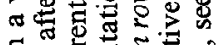

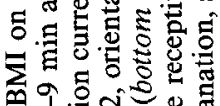

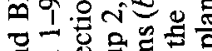

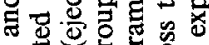

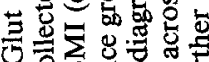

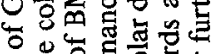

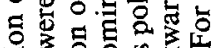

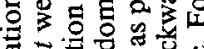

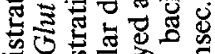

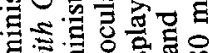
急荌

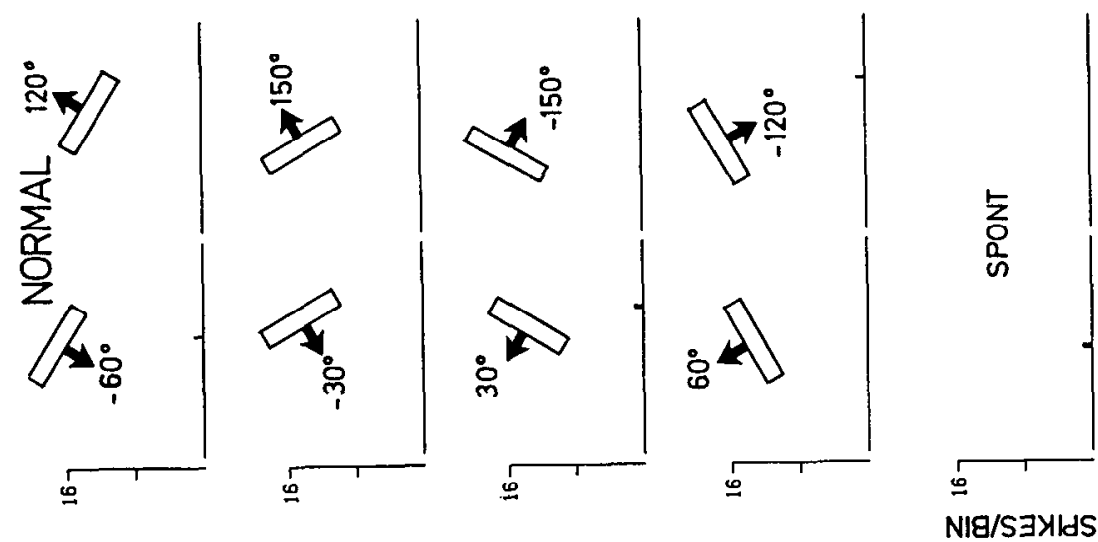

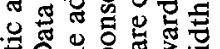

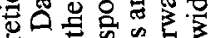

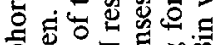
눙 吾矛员递官

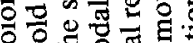
울

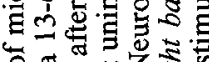

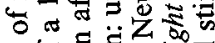

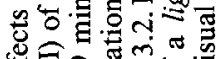

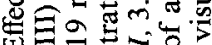
on 1 至 으ㄹㅕㅛ

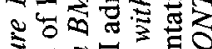

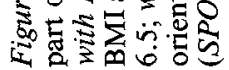


The response-to-background ratio invariably exceeded 4 when optimal stimuli were presented during BMI ejection. What had not been expected was that these neurons, after becoming visually responsive, exhibited high degrees of orientation specificity and also, in some cases, direction specificity. This is illustrated in Figures 9 and 10 . Increasing the ejection current for BMI, however, and allowing for more diffusion of the drug by waiting 5-15 min produced a reduction of the initially high degree of orientation specificity in some of these neurons (Fig. 9). By contrast, the effects of glutamate on the same neurons could be classified into 2 distinct categories. For 2 of the 7 neurons in which the effects of both drugs were measured quantitatively, thus making a direct comparison possible, glutamate had a similar effect on visual responsiveness and on functional properties as did BMI. For the other 5 neurons, glutamate did not seem to produce visual responses specific to orientation and/ or direction. One of these cases is illustrated in Figure 10. During the iontophoresis of glutamate, the cell responded to all stimulus orientations, the response-to-background ratio remaining well below 2. By contrast, the administration of BMI brought about an orientation-specific response, the response-to-background ratio exceeding 5 at the optimal orientation. As in this example and typically for the latter group of neurons, glutamate produced a significant increase in spontaneous activity when its ejection current was adjusted to levels where visual responses became apparent, whereas the iontophoretic administration of BMI had only minimal effects on spontaneous activity. These findings suggest that intracortical inhibitory mechanisms, even though less extensive than in the adult, play an active role in the immature visual cortex in suppressing the visual responsiveness of some highly orientation-specific neurons, possibly by way of a differently distributed network of inhibitory synapses than obtains in the adult (see the introduction).

\section{Pharmacological effects on visual responses and on spontaneous activity}

In $63 \%$ of the neurons tested quantitatively during administration of BMI, there was a significant increase in the discharge frequency of the activity evoked by the optimally oriented moving stimulus. In about one-fourth of this group, the increase was more than $100 \%$; however, in most cases the discharge frequency before administration of BMI was particularly low. The increase in response strength to optimal stimuli was nearly always accompanied by a moderate increase in spontaneous activity. In $12 \%$ of aill neurons, BMI did not produce an increase in the rate of activity to optimal stimuli, and in $25 \%$ of the neurons, the response frequency even decreased. This decrease was generally less than $50 \%$ and was found only in unimodal and bimodal neurons. Neurons having ON-OFF mixed receptive fields or those responding only to moving stimuli always had increased visually evoked responses during ejection of BMI.

In about one-third of the neurons, spontaneous activity remained unchanged with the levels of BMI tested; the remaining two-thirds of the cells, most of which were silent previous to BMI, fired some action potentials at frequencies of $0.1 \mathrm{~Hz}$ or less. If greater increases in firing occurred, the ejection current of BMI was reduced or its administration interrupted. The various effects of BMI on optimal responses and on spontaneous activity were seen at all ages investigated. There was no correlation between the effects of BMI on visual response and spontaneous activity, on the one hand, and on the effects on functional parameters such as orientation or direction specificity, on the other. A neuron exhibiting prominent increases or decreases in optimal response during BMI could retain its orientation specificity, and vice versa.

GABA was found to inhibit responses to optimal and nonoptimal visual stimuli with all cells tested but one. GABA also suppressed the elevated discharge of cells produced by the ejection of glutamate. In the 1 case where GABA did not suppress visually evoked activity, all functional parameters investigated during BMI administration remained unchanged. Nevertheless, the recordings seem to have been from the cell soma, since the administration of glutamate increased spontaneous activity.

\section{Discussion}

One important observation of the present study is that intracortical inhibitory processes in neonatal visual cortex appear to be much more extensively developed than had been previously thought (Blakemore and Van Sluyters, 1975; Bonds, 1979). The relatively poor orientation and direction sensitivities and immature receptive-field structures of neurons in kitten striate cortex led to the prevalent view that most functional synaptic contacts appeared later than the first few weeks of birth. The present data, however, are not in agreement with this concept, since the majority of neurons lost their orientation and/or directional selectivity during tests with BMI. The additional fact that $14 \%$ of the cells tested quantitatively could be classified as visually responsive only following BMI administration adds weight to the hypothesis (Hicks et al., 1986) that GABA-mediated inhibition in visual cortex plays an important functional role in visually inexperienced animals.

If a substantial proportion of the neurons responsible for the inhibitory processes described here are local circuit interneurons-a proposal supported indirectly by cytochemical (Hendrickson et al., 1981; Hendry and Jones, 1981; Ribak, 1978) and electrophysiological (Krnjević et al., 1970) studies-then the postsynaptic potentials observed in immature neocortex following electrical stimulation (Purpura et al., 1965) may reflect their physiological correlate in already established, fully functional synaptic connections. Also relevant to this subject are the observations of Chronwall and Wolff (1980) that autoradiographic uptake sites for GABA are present as early as embryonic day 16 in the rat occipital neocortex, and that synaptic contacts in the feline visual system are evident 3 weeks before birth (Cragg, 1975a, b; Winfield, 1981), although the majority of synapses do develop later. It has been suggested by Cragg (1975b; cf. Rogers ct al., 1974) that it may be important ontogenetically to restrict or diminish neural activity until synaptic connections are sufficiently developed for appropriate processing. On the other hand, the role of GABA-mediated inhibitory processes in neonatal visual cortex might represent instead an epiphenomenon of the "primary" purpose of GABA in neurotrophy or synaptogenesis (Wolff, 1981).

Aside from the teleological issue, the present results demonstrate that several receptive-field properties of neurons in developing visual cortex are determined by inhibitory processes mediated by GABA, and, indeed, that the visual responsiveness of neurons itself is sometimes dictated by this inhibitory amino acid transmitter. Orientation and direction specificity were often diminished, sometimes quite substantially, by the administration of BMI. This observation has been documented thoroughly by Sillito and others for the adult (Burchfield and Duffy, 1981; Sillito, 1975a, b, 1977, 1979; Sillito et al., 1980; Tsumoto et al., 1979), and has also recently been reported for the immature cortex by Sato and Tsumoto (1984). Our data show that the spatial arrangement of ON and OFF areas in bimodal fields, as well as in unimodal and mixed fields, may also change when GABA-mediated inhibition is removed. Of additional interest in this regard is our finding that no cell lost its orientation sensitivity completely during the ejection of BMI, so that the orientation biases observed previously in the geniculate of adult cats (Vidyasagar and Urbas, 1982) and kittens (Albus et al., 1983) may indeed supplement the orientation tuning of cortical 
cells, perhaps more strongly in immature than in mature cortex. This point is discussed in more depth elsewhere (Sillito, 1984) in the context of the columnar organization of the orientation domain in developing cortex.

Recently, Somogyi et al. (1984) have discussed the idea that a range of functionally distinct populations of neurons may exist in sensory cortex for the purpose of exerting inhibitory influences. These neurons may all employ $\mathrm{G} \Lambda \mathrm{B} \Lambda$ as their synaptic transmitter, though they are possibly further distinguished from each other chemically by also containing different peptides (Hendry et al., 1984); the important differences among these sets of neurons would be that they exert their varied effects independently of each other by virtue of acting at different parts of the postsynaptic neuron (axon initial segment, soma, proximal and distal dendrites) and perhaps by having their effects recognized and mediated by different classes of GABA receptors (Simmonds, 1982). Modulation by peptides, endogenous benzodiazepines, or other, as yet unknown, compounds could conspire to render the effects of GABA greater or less in potency. It may, therefore, not be surprising that in our results on some neurons, there were clear dissociations among orientation selectivity, directional selectivity, and receptive-field substructure, while on other neurons these differences were either absent or present in different combinations. Thus examples were encountered of BMI antagonizing GABA-mediated inhibitions that dictated orientation tuning, while no effect on receptive-field substructure was noted, these cells normally exhibiting the "simple" type of receptive field. Yet other cases were encountered in which the spatially separate $O N$ and OFF subregions were transformed by $\mathrm{BMI}$ into mixed $\mathrm{ON}-\mathrm{OFF}$ receptive-field types at times when no effect on orientation tuning could be detected. This stands in contrast to the results of Sillito (1975b) obtained in the adult, in which the receptive-field substructure of simple cells in layer IV was invariably lost, concomitant with the loss of orientation and direction sensitivity. One might conjecture that, in neonatal cortex, different subsets of inhibitory neurons containing GABA exert specialized functions in determining receptive-field properties and, as maturation proceeds, this functional specificity is gradually lost, the functions possibly being taken over by other sets of neurons employing transmitters different from GABA.

An alternative hypothesis, articulated by Sillito (1984), is that if the excitatory geniculate input to cortical neurons comprises overlapping ON and OFF subregions that are normally kept spatially separated by GABA-containing inhibitory interneurons-a possibility suggested by his early observation of a loss of the spatial integrity of the receptive-field substructure during BMI ejection - then the inhibitory interneuron's input must itself arise from spatially organized geniculate afferents, which provide the simple receptive-field properties to the GABA-containing cell. These neurons, then, could represent that subpopulation of simple cells that exhibited broadening of their orientation tuning or loss of directional selectivity with no concomitant loss of spatial receptive-field organization under BMI. Neurons postsynaptic to these GABA-containing cells would, of course, exhibit the dual changes in receptive-ficld topography and orientation/direction selectivity with BMI, as first described by Sillito (1975b). In support of this view are the data reported recently by Vidyasagar et al. (1985) from adult striate cortex, using drifting sine-wave grating stimuli. They found that there were only a few simple cells out of their total sample that showed significant changes in spatial and/or temporal frequency tuning under BMI, in combination with low ratio values of the amplitudes of the response components at the fundamental and 0 frequencies: Most cells maintained a high level of this "first to zero ratio," which suggests the maintained integrity of ON and OFF subregions despite the inter- ference with other GABA-mediated inhibitory receptive-field properties.

In agreement with the results of Sillito $(1977,1979)$ for adult animals is our finding that there exist subpopulations of visually reponsive neurons that appear insensitive to the orientationbroadening and direction-specific reducing effects of BMI. This observation may be explained in a number of ways. First, these neurons may receive an excitatory input that is already orientation-specific; such inputs could arise in the cortex itself and/ or in the dorsal part of the lateral geniculate nucleus (see above). Second, other inhibitory processes employing a synaptic transmitter different from GABA might provide certain cells, but not others, with their response specificity; indirect electrophysiological support for this contention has recently appeared and the issue has been discussed in the context of submodalityspecific neurons in primary somatosensory areas (Dykes et al., 1984; Hicks et al., 1985). Third, the ineffectiveness of BMI might be due to the functional operation of synaptically released GABA upon the subset of receptors now known as $\mathrm{GABA}_{\mathrm{B}}$ receptors (Bowery et al., 1981; Hill and Bowery, 1981) which are insensitive to antagonism by BMI (Simmonds, 1982) and are believed to be located presynaptically (Ault and Nadler, 1982; Bowery et al., 1980), which is possibly involved in processes of presynaptic inhibition (Levy, 1977). Last, it is possible that the occasional ineffectiveness of BMI resulted not from any of the above physiological reasons, but rather from a diffusion of antagonist following iontophoretic expulsion insufficient to limit the reaction with the subsynaptic GABA receptors located on dendritic surfaces distal to the pipette orifice, despite the fact that high currents were often applied for long durations. This situation might arise from unusual geometrical relations between soma and dendritic field of particular cells (Hicks, 1983), rather than from pipette-induced artifacts such as inoperative drug barrels, for example, since other neurons in the same penetrations exhibited altered receptive-field properties in response to BMI ejected from the same pipette assemblies. Methodological and practical considerations pertaining to diffusion and drug spread through brain tissue following iontophoresis have been reviewed in detail elsewhere (Hicks, 1984). The issue of the unmasking of visual responsiveness in previously unresponsive neurons with BMI is also of considerable interest, as it raises the issue of the nature of the inhibitory processes at work on these cells, which formed over $15 \%$ of our sample. These neurons are likely to receive different types of inhibitory inputs: from orientation-nonspecific and from orientation-sensitive neurons. Orientation-nonspecific inputs are indicated by the greater probability of occurrence of BMI-reversed, visually unresponsive neurons (Table 1) in younger cortices, where the proportion of orientation-nonselective neurons is higher and where the unmasked visual responses are often more broadly tuned than in the older group. The other input is probably from orientation-sensitive neurons, and is more resistant to the effects of BMI, as demonstrated by the higher currents of ejection required before orientation tuning was broadened, even though visual responsiveness itself had been unmasked. Possible explanations of this relative resistance to BMI might include the use of a relatively denser population of GABA synapses mediating orientation properties than mediating response threshold; a differential distribution of synapses along the dendritic arbors or the initial segment region; or different strengths of GABA-mediated synaptic inputs operating in these 2 domains, dictated, perhaps, by differential modulation through benzodiazepine processes or the peptide-mediated modulating influence.

A final comment regarding the nature of the receptors reacting with GABA and concerning the question of whether the inhibitory mechanism studied here involves synaptic or extrasynaptic 
receptors for the amino acid: That GABA is capable of an action both on synaptic and extrasynaptic populations of receptors is well recognized (Curtis and Johnston, 1974; Simmonds, 1982). Since the iontophoretically administered amino acid nonselectivity depresses visual activation, it is reasonable to assume that this physiologically "nonspecific" depression arises through the interaction of GABA with receptors not involved in dictating orientation or directional shaping of the naturally elicited response. Whether these receptors are involved in different synaptic events cannot be ascertained on the basis of these experimcnts. The results with BMI, however, permit a greater interpretive latitude, since any alteration in response properties evolving from the administration of a pharmacologically specific antagonist is necessarily demonstrative of the interruption of intrinsically operative, synaptic processes. Therefore, the broadcning of oricntation tuning, the reduction in direction selectivity, and the breakdown in receptive-field structure observed with BMI all signify the involvement of GABA-mediated synaptic inhibition. Although not studied in detail here, it is noteworthy that potency differences among cells in other sensory regions (Dykes et al., 1984; Koyama et al., 1980) have becn notcd for GABA and, while quantitative treatment of such data is difficult owing to interpretive difficulties with the microiontophoretic method (Hicks, 1984), it is likely nonetheless that uneven distributions of synaptic and extrasynaptic populations of receptors would contribute to such differential sensitivities.

\section{References}

Albus, K., and W. Wolf (1984) Early post-natal development of neuronal function in the kitten's visual cortex: A laminar analysis. J. Physiol. (Lond.) 348: 153-185.

Albus, K., W. Wolf, and R. Beckman (1983) Orientation bias in the response of kitten LGNd neurones to moving light bars. Dev. Brain Res. 6: 308-313.

Ault, B., and V. Nadler (1982) Baclofen selectively inhibits transmission at synapses made by axons of $\mathrm{CA}^{3}$ pyramidal cells in the hippocampal slice. J. Pharmacol. Exp. Ther. 223: 291-297.

Barlow, A. B., C. Blakemore, and J. D. Pettigrew (1967) The neuronal mechanism of binocular depth discrimination. J. Physiol. (Lond.) 193: 327-342.

Blakemore, C., and R. C. Van Sluyters (1975) Innate and environmental factors in the development of the kitten's visual cortex. J. Physiol. (Lond.) 248: 663-716.

Bonds, A. B. (1979) Development of orientation tuning in the visual cortex of kittens. In Developmental Neurobiology of Vision. R. D. Freeman, ed., pp. 31-41, Plenum, New York.

Bowery, N. G., A. Doble, D. R. Hill, A. L. Hudson, D. N. Middlemiss, J. Shaw, and M. J. Turnbull (1980) (-) Baclofen decreases neurotransmitter release in the mammalian CNS by an action at a novel GABA receptor. Nature 284: 92-94.

Bowery, N. G., A. Doble, D. R. Hill, A. L. IIudson, J. S. Shaw, M. J. Turnbull, and R. Warrington (1981) Bicuculline-insensitive GABA receptors on peripheral autonomic nerve terminals. Eur. J. Pharmacol. 71: 53-70.

Buisseret, P., and M. Imbert (1978) Visual cortical cells: Their developmental properties in normal and dark reared kittens. J. Physiol. (Lond.) 255: 511-525.

Burchfield, J. L., and F. H. Duffy (1981) Role of intracortical inhibition in deprivation amblyopia reversal by microiontophoretic bicuculline. Brain Res. 206: 479-484.

Chronwall, B., and J. R. Wolff (1980) Prenatal and postnatal development of GABA-accumulating cells in the occipital neocortex of rat. J. Comp. Neurol. 190: 187-208.

Cragg, B. G. (1975a) The development of synapses in the visual system of the cat. J. Comp. Neurol. 160: 147-166.

Cragg, B. G. (1975b) The development of synapses in kitten visual cortex during visual deprivation. Exp. Neurol. 46: 445-451.

Curtis, D. R., and G. A. R. Johnston (1974) Amino acid transmitters in the mammalian central nervous system. Ergebn. Physiol. 69: 97188.

Dykes, R. W., P. Landry, R. Metherate, and T. P. Hicks (1984) Func- tional role of GABA in cal primary somatosensory cortex: Shaping receptive fields of cortical neurons. J. Neurophysiol. 52: 1066-1093.

Fregnac, Y., and M. Imbert (1978) Early development of visual cortical cells in normal and dark-reared kittens: Relationship between orientation selectivity and ocular dominance. J. Physiol. (Lond.) 278 : 27-44.

Hendrickson, A. E., S. P. Hand, and J.-Y. Wu (1981) Immunocytochemical localization of glutamic acid decarboxylase in monkey striate cortex. Nature 292: 605-607.

Hendry, S. C. H., and E. G. Jones (1981) Sizes and distributions of intrinsic neurones incorporating tritiated GABA in monkey sensorimotor cortex. J. Neurosci. 4: 390-408.

Hendry, S. C. H., J. DeFelipe, and E. G. Jones (1984) Peptide-like immunoreactivity coexists with glutamic acid decarboxylase immunoreactivity in neurones of cal and monkey cerebral cortex. Soc. Neurosci. Abstr. 10:693.

Henry, G. H., P. O. Bishop, R. M. Tupper, and B. Dreher (1973) Orientation specificity and response variability of cells in the striate cortex. Vision Res. 13: 1771-1779.

Heyer, E. J., L. M. Nowak, and R. L. MacDonald (1981) Bicuculline: A convulsant with synaptic and nonsynaptic actions. Neurology 31 : 1381-1390.

Hicks, T. P. (1983) Antagonism of synaptic transmission in vivo: Contributions of microiontophoresis. Brain Behav. Evol. 22: 1-12.

Hicks, T. P. (1984) The history and development of microiontophoresis in experimental neurobiology. Prog. Neurobiol. 22: 185-240.

Hicks, T. P., and R. W. Dykes (1983) Receptive field size for certain neurones in primary somatosensory cortex is determined by GABAmediated intracortical inhibition. Brain Res. 274: 160-164.

Hicks, T. P., and R. C. A. Guedes (1983) Neuropharmacological properties of electrophysiologically identified, visually responsive neurones of the posterior lateral suprasylvian area. A microiontophoretic study. Exp. Brain Res. 49: 157-173.

Hicks, T. P., P. Landry, R. Metherate, and R. W. Dykes (1985) Functional properties of neurons mediated by GABA in cat somatosensory cortex under barbiturate and urethane anesthesia. In Development, Organization, and Processing in Somatosensory Pathways, W. D. Willis and M. J. Rowe, eds., pp. 265-276, Alan R. Liss, New York.

Hicks, T. P., W. D. Ruwe, and W. L. Veale (1986) Release of $\gamma$-aminobutyric acid from the visual cortex of young kittens. Dev. Brain Res. 24: 299-304.

Hill, R. G., and N. G. Bowery (1981) ${ }^{3} \mathrm{H}-$ baclofen and ${ }^{3} \mathrm{H}-\mathrm{GABA}$ bind to bicuculline-insensitive $\mathrm{GABA}_{\mathrm{B}}$ sites in rat brain. Nature $290: 149$ 152.

Horsley, V., and R. H. Clarke (1908) The structure and function of the cerebellum examined by a new method. Brain 31: 45-124.

Hubel, D. H., and T. N. Wiesel (1962) Receptive fields, binocular interaction and functional architecture in the cat's visual cortex. $\mathrm{J}$. Physiol. (Lond.) 160: 106-154.

Hubel, D. H., and T. N. Wiesel (1963) Receptive fields of cells in striate cortex of very young, visually inexperienced kittens. J. Neurophysiol. 26: 994-1002.

Koyama, Y., Y. Fukuda, and K. Iwama (1980) GABA sensitivity of neurones in the visual layer in the rat superior colliculus. Brain Res. 192: 121-131.

Krnjević, K., R. J. Reiffenstein, and A. Silver (1970) Chemical sensitivity of neurones in long-isolated slabs of cat cerebral cortex. EEG Clin. Neurophysiol. 29: 269-282.

Levy, R. A. (1977) The role of GABA in primary afferent depolarization. Prog. Neurobiol. 9: 211-267.

Meyer, G., and R. Ferres-Torres (1984) Postnatal maturation of nonpyramidal neurones in the visual cortex of the cat. J. Comp. Neurol. 228: 226-244.

Nowak, L. M., A. B. Young, and R. L. MacDonald (1982) GABA and bicuculline actions on mouse spinal cord and cortical neurones in cell culture. Brain Res. 244: 155-164.

Olson, R. W. (1982) Drug interaction at the GABA receptor-ionophore complex. Annu. Rev. Toxicol. 22: 245-277.

Otsuka, R., and R. Hassler (1962) Der Aufbau und Gliederung der corticalen Sehsphäre bei der Katze. Arch. Psychiat. Neurol. 203: 212234.

Purpura, D. P., R. J. Shofer, and T. Scarff (1965) Properties of synaptic activities and spike potentials of neurones in immature neocortex. $J$. Neurophysiol. 28: 925-942. 
Ribak, C. E. (1978) Aspinous and sparsely-spinous stellate neurones in the visual cortex of rats contain glutamic acid decarboxylase. J. Neurocytol. 7: 461-478.

Rogers, L. J., H. D. Drennen, and R. F. Mark (1974) Inhibition of memory formation in the imprinting period: Irreversible action of cycloheximide in young chickens. Brain Res. 79: 213-233.

Sato, H., and T. Tsumoto (1984) GABAergic inhibition already operates on a group of neurones in the kitten visual cortex at the time of eye opening. Dev. Brain Res. 12: 311-315.

Sillito, A. M. (1975a) The effectiveness of bicuculline as an antagonist of GABA and visually evoked inhibition in cat's striate cortex. J. Physiol. (Lond.) 250: 287-304.

Sillito, A. M. (1975b) The contribution of inhibitory mechanisms to the receptive field properties of neurones in the striate cortex of the cat. J. Physiol. (Lond.) 250: 305-329.

Sillito, A. M. (1977) Inhibitory processes underlying the directional specificity of simple, complex, and hypercomplex cells in the cat's visual cortex. J. Physiol. (Lond.) 271: 699-720.

Sillito, A. M. (1979) Inhibitory mechanisms influencing complex cell orientation selectivity and their modification at high resting discharge levels. J. Physiol. (Lond.) 289: 33-53.

Sillito, A. M. (1984) Functional considerations of the operation of GABAergic inhibitory processes in the visual cortex. In Cerebral Cortex, Vol. 2, Functional Properties of the Cortical Cells, E. G. Jones and A. Peters, eds., pp. 91-117, Plenum, New York

Sillito, A. M., J. A. Kemp, J. A. Milson, and N. Berardi (1980) A reevaluation of the mechanisms underlying simple cell orientation selectivity. Brain Res. 194: 517-520.

Simmonds, M. A. (1982) Classification of some GABA antagonists with regard to site of action and potency in slices of rat cuneate nucleus. Eur. J. Pharmacol. 80: 347-358.

Somogyi, P., T. F. Freund, and Z. F. Kisvarday (1984) Different types of ${ }^{3} \mathrm{H}-\mathrm{GABA}$ accumulating neurones in the visual cortex of the rat.
Characterization by combined autoradiography and Golgi preparations. Exp. Brain Res. 54: 45-56.

Straughan, D. W., M. J. Neal, M. A. Simmonds, C. G. S. Collins, and R. G. Hill (1971) Evaluation of bicuculline as a GABA antagonist. Nature 233: 352-354.

Tsumoto, T., W. Eckart, and O. D. Creutzfeldt (1979) Modification of orientation sensitivity of cat visual cortex neurones by removal of GABA mediated inhibition. Exp. Brain Res. 34: 351-363.

Vidyasagar, T. R., and J. V. Urbas (1982) Orientation sensitivity of cat LGN neurones with and without inputs from cortical areas 17 and 18. Exp. Brain Res. 46: 157-169.

Vidyasagar, T. R., A. Müller, and B. B. Lee (1985) Effects of bicuculline on the responses of cat striate cortical cells to moving sine-wave gratings. Neurosci. Lett. (Suppl.) 22: 297.

Winfield, D. A. (1981) The postnatal development of synapses in the visual cortex of the cat and the effects of eyelid closure. Brain Res. 166-177.

Winfield, D. A. (1983) The postnatal development of synapses in the different laminae of the visual cortex in the normal kitten and in kitten with eyelid closure. Dev. Brain Res. 9: 155-169.

Wolff, J. R. (1981) Evidence for a dual role of GABA as a synaptic transmitter and a promoter of synaptogenesis. In Amino Acid Neurotransmitters, F. V. DeFeudis and P. Mandel, eds., pp. 459-465, Raven, New York.

Wolff, J. R., H. Böttcher, T. Zetzsche, W. H. Oertel, and B. M. Chronwall (1984a) Development of GABAergic neurons in rat visual cortex as identified by glutamate decarboxylase-like immunoreactivity. Neurosci. Lett. 47: 207-212.

Wolff, J. R., V. J. Balcar, T. Zetzsche, H. Böttcher, O. E. Schmechel, and B. M. Chronwall (1984b) Development of GABAergic system in rat visual cortex. In Gene Expression and Cell-Cell Interactions in the Developing Nervous System, J. M. Lauder and P. Nelson, eds., pp. 215-224, Plenum, New York. 